\title{
EL NACIONALISMO Y LA ARQUITECTURA
}

\section{XAVIER MOYSSÉN}

\section{A Louise Noelle}

Hay países que cuentan en su haber con un pasado admirable en sus manifestaciones culturales, mismas que suelen hacer acto de presencia como valores dignos de ser considerados si las razones de unos fines deliberadamente trazados así lo ameritan. Estos fines bien pueden abedecer a los principios de una política de exaltación nacionalista, o en su defecto a cuestiones relacionadas con la búsqueda de una expresión que permita definir lo que es propio, frente a lo existente allende las fronteras. El vigoroso pasado cultural de algunos países permanece latente, se manifiesta constantemente; es una herencia firme y distintiva que les pertenece, no obstante que esa herencia quede englobada dentro de los valores de carácter universal.

México está colocado en una situación singular dentro del ámbito de las grandes culturas, ya que es un país que posee como legado histórico un patrimonio artístico que no es exagerado calificar de monumental. Tal legado corresponde a distintos periodos dentro del transcurso de los siglos; sin embargo, el periodo que representa la máxima originalidad en cuanto a valores propios, es el Prehispánico, y su presencia es indestruc. tible. Desde la caída de Tenochtitlan su influencia, a pesar de todo, no ha cesado, en una forma o en otra se mantiene viva; a ello obedece, por ejemplo, el que en algunas ocasiones los artistas se lleguen al antiguo mundo indígena, en un afán de encontrar una identidad que les muestre distintos ante lo extranjero. Para mucho es como rescatar una parte esencial de lo que pertenece al pueblo del que se forma parte.

Así ha sucedido.con la arquitectura, tema central de este trabajo con el que se pretende mostrar mediante algunos ejemplos, acaso los más sig. nificativos, cómo se ha echado mano de la expresión formal de la arqui. tectura prehispánica, con el propósito de mostrar ciertos valores existentes en los vetustos edificios y su posible utilización, como una propuesta en favor de lo que es propio y distintivo de México. Para esta investigación se han fijado unos límites que abarcan los años que van de 1889 a 1976; a la primera fecha corresponde el pabellón que México levantó para la Exposición Internacional de París, en tanto que a la segunda, la gran obra del Colegio Militar, situado en los linderos de la capital. 
La arquitectura prehispánica sólo ha ofrecido soluciones formales tanto de volumen como decorativas, a quienes se han llegado hasta ella en pos de sus rasgos característicos, para recrearlos y aplicarlos de nueva cuenta en las obras que edifican. Nada se puede tomar prácticamente de la herencia indígena, en lo que se refiere a estructuras, composición y espacios habitables, dado el desconocimiento que se tuvo, entre otras cosas, del arco y de la bóveda. Ante la ausencia de arcos para cerrar vanos, se empleó el dintel lítico o de madera; el mal llamado "arco maya" y la bóveda consiguiente, ya se sabe que no fue otra cosa que una construcción en saledizo. Los principios de las cubiertas de las tumbas de Monte Albán o Mitla, no llegaron a más pues sus proyecciones en sí exan limitadas. La arquitectura prehispánica fue de reducidos espacios interiores. Favoreció en cambio, la organización de enormes espacios abiertos en el exterior, modelados éstos por las masas escalonadas de las pirámides, poí los basamentos de los adoratorios y por la ornamentación misma, abundante entre algunos pueblos tanto en relieves como esculturas exentas y encima de todo, una pródiga policromía.

Gracias a las investigaciones realizadas por arqueólogos y antropólogos, es posible precisar con cierta propiedad, sobre el carácter que guardaban los recintos prehispánicos tanto en su interior como exteriormente. Las reconstrucciones históricas que se hicieron hasta el siglo XIx, no pasaron de ser buenas intenciones, o verdaderas fábulas, por más acopio de informaciones que hayan tenido sus autores; pero no es honrado exigirles más, sobre todo si se les juzga conforme a la luz del conocimiento arqueológico que hoy se posee. Quizá la mejor muestra de los conceptos que se tenían con respecto a las estancias ocupadas por los gobernantes indígenas, sean dos pinturas académicas; una de ellas, debida a José Obregón, está relacionada con el tema del Descubrimiento del pulque. En la tela aparece una animada escena en una "sala del trono", en la que una bella joven indígena, tratada a la manera de vestal romana, hace entrega del líquido recién descubierto, a un joven cacique de rebuscada apariencia, quien se encuentra bajo un baldaquín y sentado en su "trono". Toda la composición de la escena depende en una forma o en otra, de alguna estampa neoclásica. Si la reconstrucción histórica de los personajes resulta falsa, no es menos la que se hizo sobre el enorme interior del aposento.

Sólo una pródiga fantasía permitió realizar la reconstrucción del gxan salón de mando de los señores mexicas, según aparece en el segundo cuadro, titulado Los informantes de Moctezuma, pintado hacia 1898 por Isidro Martínez (figura 1). En medio de una fastuosidad convencional 
se encuentra Moctezuma, rodeado de su corte y ante los informantes que le llevan noticias del arribo de unos hombres blancos y barbados a la costa de Veracruz. Cobija a la colorida escena, la arquitectura de una sala increíble por sus proporciones y por los elementos constructivos que hay en ella, desde unas enormes pilastras estípites sobre las que posan unos fabulosos dragones que han sustituido a las serpientes, hasta una amplia puerta adintelada en cuyo centro se levanta una escultura que viene a ser una réplica de las famosas cariátides de Tula; no falta una especie de friso y las consabidas grecas. Al parecer la estancia está cubierta por una techumbre. Este tipo de reconstrucciones pictóricas deben considerarse como un producto de la fantasía arqueológica decimonónica, misma que se brincaba los limitados conocimientos que en la época se poseían; tal hecho se repitió en las obras de arquitectura inspiradas en lo prehispánico.

El gobierno francés invitó al de México a participar en la exposición internacional que se llevaría a efecto en París en 1889. Al aceptar Porfirio Diaz la invitación, independientemente del honor que para los mexicanos significaba tal distinción, lo hizo atendiendo a razones de mayor importancia: con la asistencia a la exposición se apagarían en definitiva los rescoldos dejados por la no lejana intervención gala en el país y como éste se encontraba en ese momento en un periodo de franca recuperación, era necesario dar muestras de que era amante de la paz y del progreso, cosas necesarias para atraer a los inversionistas que aquí se requerian.

Se abrió un concurso para levantar un pabellón en la Ciudad Luz, en donde se mostrarian los productos naturales y los elaborados, más las obras de arte que México enviaría. En la convocatoria se precisó que el edificio debía tener como característica principal, el representar lo que se consideraba el espíritu nacional y éste no era otro, en ese momento, que el indígena o prehispánico. Se presentaron dos proyectos, uno del arquitecto Antonio M. Anza, quien se hizo asesorar por el conocido arqueólogo Antonio Peñafiel; la otra proposición fue la del ingeniero arquitecto Luis Salazar, auxiliado por Vicente Reyes y José M. Alva. El proyecto triunfante fue el de Anza y Peñafiel. ${ }^{1}$

1 No fue ésta la primera ocasión en la que México mostraxa en París la arquitectura prehispánica o edificios inspirados en la misma. Para la Exposición Internacional de 1867. Maximiliano autorizó a Desiré Charnay la construcción del pabellón, el cual resultó una extrañísima réplica. "a escala natural, ¡del Templo de Quetzalcóatl de 
El enorme edificio, con dos niveles, albergaba tres salas de las cuales la principal era la del centro. Exteriormente medía sesenta metros de largo por treinta de ancho y catorce y medio de altura. En la composición de la portada se recalcó el interés en el núcleo central; en él se tendía una escalinata sin alfardas, pues en su lugar se dispusieron toscas bases para soportar braseros dedicados al dios Huehueteotl. La parte inferior del edificio, tratada como basamento, seguía el diseño de los taludes; gruesas bandas, decoradas al parecer con grecas, recorrían el perímetro de los muros. La solución adoptada para la parte superior, evitó los vanos, en lugar de éstos se colocaron unos recuadros para contener en número de doce, grandes relieves fundidos en bronce. Dos puertas de acceso se localizaban en los extremos del basamento, mientras que en la parte alta, frente a la escalinata, se abría un amplio vano cuyo dintel era soportado por dos cariátides, semejantes a las de Tula, según se dijo. El remate del conjunto era una curiosa mezcla de motivos entre europeos e indígenas con "la gran figura del sol, Tonatiuh" (figuras 2 y 3).

Los relieves de bronce, de factura muy discutible, le fueron encargados al escultor Jesús F. Contreras (1866-1902). Formalmente eran demasiado convencionales y representaban, según disposición de Peñafiel, tanto a la mitología como a la historia; entre las deidades se hallaban Tlaloc, Centeotl, Chalchiuhtlicue, Camaxtli, Xochiquetzal y Yacatecutli, y entre los señores, Ixcoatl, Netzahualcoyotl, Totoquihuatzin, Cacama, Cuitlahuac y Cuauhtémoc.

No es ocioso el transcribir una mínima parte de la descripción que chl pabellón hiciera el propio Peñafiel:

El edificio está construido en el estilo azteca más puro y de los materiales (sic) de mi obra Arte Mexicano Antiguo... ha merecido también la aprobación de distinguidos y eminentes anticuarios que han consagrado su vida y su inteligencia a los difíciles estudios de la Arquedlogía Mexicana... tiene elementos tomados de las llamadas murallas de Huexotla, Xochicalco...2

Xochicalco! Afortunadamente han quedado fotografías de la época, donde se puede apreciar la incongruencia del dicho pabellón, a cuya entrada estaban Coatlicue y el llamado Calendatio Azteca", Véase, Beatriz de la Fuente, " $\mathrm{BI}$ arte prehispánico visto por los europeos del siglo xx", en Revista de la Universidad de México, núm. 32, México, diciembre de 1983 , p. 6. Me es grato manifestar mi agradecimiento al arquitecto Daniel Schávelson, por su ayuda en la investigación de este trabajo, debido a su generosidad consulté el texto inédito de su libro Ia polémica del "arte nacional" en México 1850-1910 (Antologia).

2. Antonio Peñafiel, Explicación del edificio mexicano para la Exposición Interna. cional de Paris, México, 1889 . 
EI interior del pabellón era otra cosa; se trataba de tres amplios espacios construidos con los materiales de la época, o sea, estructuras de hierro con techos de vidrio. Los dos niveles daban lugar a largos corredores; en la sala mayor se tendía, al centro, una escalera doble fabricada también con metal. En cuanto a la axquitectura, bien se podía decir que del pasado arqueologizante del exterior, se pasaba al presente (figura 4).

En la amplia sala principal se exhibió toda clase de objetos, como sencillas manufacturas, productos del campo y muestras de la riqueza minera. También se mostraban algunas piezas arqueológicas y entre otras curiosidades se incluyeron varias maquetas, como la del monumento a Cuauhtémoc, colocada frente a la que representaba la sensación del momento: la Torre Eiffel. El ar te mexicano de la época hizo acto de pre. sencia con las pinturas del paisajista José María Velasco y otros artistas, mismas que se instalaron en una sala lateral, pues hubo un rechazo de parte del jurado internacional de admisión para que las obras que envia. ron los países latinoamericanos fueran exhibidas en el Palacio de las Bellas Artes, en donde se mostraban las pinturas y esculturas de los artistas euro. peos; sin embargo, no sucedió lo mismo con el envío de los norteamericanos, a quienes dieron tres galerías para exponer sus obras.

El proyecto que al concurso presentaron Luis Salazar y compañeros tenía un carácter distinto. Constaba también de dos plantas; en la composición de la fachada dispusieron un núcleo central y dos torres en los extremos. Las puertas de una altura exagerada, obedecían a un diseño trapezoidal, como también las ventanas y balcones del segundo piso, mas no las del primero. La decoración que debía cubrir los muros con una especie de horror al vacío, era una verdadera mezcolanza de motivos tomados de aquí y de allá; otro tanto sucedia con el remate central y las almenas, pues para elaborar su proposición arquitectónica, los autores se documentaron en dos fuentes; la primera era la de los monumentos de Mitla, Chichén Itzá, Palenque, Xochicalco y Teotihuacan, entre otros; la segunda se encontraba en los libros que consultaron, como los de Dupaix, Waldek, Lord Kinsborough y Chavero, véase la figura 5. En defensa de su proyecto Salazar publicó en 1899, una detallada descrip. ción del mismo, puesto que pretendía que se construyera para la Expo. sición Internacional de 1900 que se verificaría en París. 3

3 Apareció en tres entregas de la revista El arte y la ciencia, con el título de "La

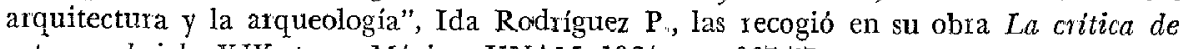
arte en el siglo XIX, t. III, México, UNAM, 1964, pp. 367-77. 
Tanto el edificio de Antonio M. Anza como el proyecto de Luis Salazar, alcanzaron la censura y la condena por parte de la crítica que les hicieron aquellos que comprendían lo falsa que resultaba la salida que se queria dar en favor de una arquitectura nacional, inspirada en la herencia prehispánica. Entre los censores se encontraban el arqueólogo Leopoldo Batres y los arquitectos Manuel Francisco Álvarez (quien ade. más ostentaba el título de ingeniero) y Francisco Rodríguez.

Leopoldo Batres desde su punto de vista comentó lo siguiente:

Cuando se ha pretendido hacer renacer la arquitectura y la decoración arquitectónica de algunas de las diferentes tribus o razas que habitaron lo que hoy se llama la República Mexicana, se ha caído siempre en un error de fantasía que ha pasado inadvertido comúnmente, por tratarse de reconstruir arquitecturas no estudiadas ni conocidas, por ejemplo, en los momentos que escribo estas líneas, se levanta en París, en el Campo de Marte, el edificio mexicano que debe servir de palacio o pabellón para los productos y objetos de México en el gran certamen de la Exposición de 1889. A este edificio se le quizo dar la forma azteca y no se consiguió sino hacer un gran local sin estilo determinado... lo mismo sucede en la decoración arquitectónica en general. Si a un edificio mexica o tolteca se le pone por decoración mural en su parte exterior grandes tableros con relieves representando figuras históricas y mitológicas, se cae en grandísimo error y anacronismo, porque esos motivos de decoración, fueron única y exclusivamente peculiares de la raza maya ${ }^{4}$

Manuel Francisco Álvarez comprendió, en su momento, lo absurda que era la convocatoria para la construcción de un "edificio que recordara la antigua arquitectura mexicana"; previendo el fracaso que tal obra sería, se opuso a su realización con la autoridad que poseía dentro de la cultura del régimen de Porfirio Díaz; mas al comprender lo infructuosa que era cualquier protesta, "por estar resuelta (ya) la construcción de tal edificio", desistió de toda gestión que lo evitara y sólo escribió sobre lo mismo, años más tarde. 5 A él se debe la curiosa noticia de cómo el propio Batres había sucumbido ante el revizul indígena, nada menos que en su casa; al referirse a ello aprovechó la ocasión para hacer la condena de los arqueologismos en la arquitectura, he aquí sus palabras: "... el señor Leopoldo Batres. . hace pocos años construyó su propia casa-. habitación y arregló la fachada con motivos de la arquitectura india; así

4 Citado por Manuel Francisco Álvarez en Las winas de Milla y la arquitectura nacional, México, 1900, pp. 276-77

5 Ibidem, pp. $274-75$ 
estuvo por algún tiempo y de repente la hizo desaparecer, sustituyéndola por otra de otro estilo". Concluye de manera categórica, "sin comentario de ninguna especie, sin querer averiguar el fundamento de tal determinación, sin entrar en el análisis crítico de aquella fachada, ¿̨su desaparición, no es la mejor prueba del abandono que se debe hacer de la arquitectura histórica mexicana y que no se debe pensar más en resucitarla?" 6

Por su parte el arquitecto Francisco Rodríguez, que se escudaba bajo el seudónimo chusco de Tepoztecaconetzin Calquetzani, ante la amenaza de que el proyecto de Luis Salazar se aprovechara para la exposición de 1900, escribió lo siguiente a propósito del pabellón de Antonio M. Anza:

En ese edificio no hubo distinción de forma ni distinción de necesidades: miembros arquitectónicos de todos los estilos exornaron el conjunto, ocupando el lugar que convino; se fracturó la estructura sin piedad y la imaginación tomó el vuelo de la fantasía. . . iNuestro edificio nos exhibió en época anterior a la conquista española! ¡Con cuán poco acierto! Pretendiéndose hacerlo azteca, pero se tomaron sin el menor escrúpulo elementos arquitectónicos de las civilizaciones del antiguo mundo, haciéndoles desempeñar funciones diversas de las que correspondian originaria y racionalmente. ${ }^{7}$

Salvo el caso de Luis Salazar, ignoro si alguien más salió en defensa del pabellón levantado por Antonio M. Anza y Antonio Peñafiel. En su trabajo citado en la nota 3, Salazar esgrimió argumentos no sólo en favor de aquéllos, también lo hizo respecto al proyecto que presentó. Él propugnaba porque las jóvenes generaciones de arquitectos fueran educadas para aceptar como algo propio y sin mayor problema la herencia de lo prehispánico, pues allí estaba la razón de ser de la arquitectura que pedia para el país.

No obstante los argumentos de rechazo las pretensiones por revivir la antigua arquitectura seguían adelante, y 1899 resultó un año apropiado para ello, pues en la capital de la República se edificaron para las celebraciones patrias de la Independencia, más "el onomástico de Porfirio Díaz, el 15 de septiembre, y el triunfo de la campaña política para una nueva reelección 1900-1904", 8 varias "puertas de triunfo", a semejanza de los viejos arcos triunfales, en las que se adaptaron formas y motivos

6 Ibidem, p. 280.

7 Su artículo fue pubicado en $E l$ arte y la ciencia, bajo el título de "Arquitectura, arqueologia y arquitecturas mexicanas", vide, Ida Rodriguez, op. cit., pp. 377-80.

8 Elisa García Barragán, " La exaltación efímera de la vanidad", en $E l$ arte efimero en el mundo hispánico, México, UNAM, 1983, pp. 286-90. 
procedentes de Ia arquitectura indígena. La correspondiente al Estado de Oaxaca era zapoteca, su autor intelectual fue el historiador Alfredo Chavero; en tanto que la puerta de Yucatán se construyó bajo la dirección de Leopoldo Batres, colaboró con él el escultor Enrique Alciati (figura 6).

Nada tan apropiado para enaltecer, hasta el delirio, a un dictador como Porfirio Díaz, que el erigirle un gran monumento, y si éste es como el que proyectó el arquitecto Adamo Boari, en 1900, se alcanza lo sublime. Según el proyecto, el monumento estaría formado por tres cuerpos, mismos que se desprendían de un gigantesco bloque de mármol, labrado afanosamente por ángeles escultores. El primer cuerpo, encerrado en un estrecho cuadrángulo formado por ocho serpientes cuyas colas se anudaban en los ángulos, no era otra cosa que un fantástico basamento piramidal con alfardas, escalinatas y unos conjuntos escultóricos en los que sobresalían réplicas de la cabeza de la diosa Coyolxauhqui; guirnaldass de flores colgaban sobre estas esculturas. Como se ve Boari no escapó a la tentación de rescatar la arquitectura prehispánica para incorporarla a su monumento; por esos años él escribió lo siguiente: “... no es preciso renegar el pasado, hoy más que nunca cada país debe hacer gala de sus formas arquitectónicas típicas modernizándolas". ${ }^{9}$ Aunque se refería a otra obra, en realidad esas palabras en el caso del monumento a Díaz le justificaban como practicante que era del eclecticismo. Por otra parte, Adamo Boari gustaba de integrar la jardinería con la arquitectura, de ahí que nada raro resulte el hecho de que sobre el basamento piramidal dispusiera un pequeño jardín, en el cual no escaseaban los magueyes floridos y las nopaleras. En el cuerpo central debían colocarse los ángeles que esculpían el monumento; en tanto que en el tercero se levantaba un templete de arquitectura clásica, mismo que servía de base a la escultura ecuestre de Porfirio Díaz, quien apoteósicamente agitaba por los vientos una enorme bandera. Mediante el empleo de formas artísticas Adamo Boari, reunía lo indígena americano con la tradición clásica euro. pea. A nadie más que a un italiano se le pudo ocurrir tal monumento, ${ }^{10}$

Con la exaltación nacionalista que trajo consigo la Revolución iniciada en 1910 , fue posible la recuperación de los valores culturales de México, un tanto cuanto relegados por la aceptación de lo francés durante el régi-

9 Citado por Juan Urquiaga en la presentación del catálogo La construcción del Palacio de Bellas Artes, exposición presentada el mes de septiembre, México, INBA, 1984, p. 3.

10 El proyecto de Adano Boari lo publicó Justino Fernández en 1937, en El arte moderno en México (figura 103). 
men de Porfirio Díaz. Entre esos valores se encontraba el arte, tanto el prehispánico como el colonial y como novedad surgió el descubrimiento consciente de las artesanías populares, las cuales de manera silenciosa pero persistente, se mantenían inalterables en su esencia hasta ese momento, en los apartados centros de su producción. ${ }^{11 .}$ Respecto a la arquitectura el nacionalismo se fijó en las dos únicas fuentes que podían ofrecer la posibilidad de alcanzar la identidad perdida: la de las culturas indígenas precolombinas y la del periodo colonial; por razones obvias en lo constructivo, se impuso la segunda. La arquitectura virreinal reapareció, pues para algunos representaba en cierta manera lo religioso, como una reacción contra el jacobinismo liberal del siglo xIx; para otros, en cambio, era una posibilidad de alcanzar lo propio mediante una tradición que tarde o temprano debía superarse. Mientras esto último se lograba la herencia colonialista hizo acto de presencia en un gran centro educativo que el gobierno de Álvaro Obregón construyó bajo el amparo del ministro de educación, José Vasconcelos, dueño de una mente de ideas revo. lucionarias, pero estancada en cuanto a una nueva arquitectura, propia de su tiempo. La Escuela Benito Juárez fue edificada en 1923 por el arquitecto Carlos Obregón Santacilia, quien la proyectó más como un edificio para una comunidad religiosa, que para un centro escolar de carácter revolucionario. No obstante, la tendencia prehispánica no desapareció como habremos de ver.

Hacia 1922 en la Escuela de Arquitectura se presentó un estudio para un "capitel mexicano", inspirado en las raíces más profundas del nacionalismo indigenista, capitel que superaba con creces el que el arquitecto Antonio Rivas Mercado había diseñado doce años atrás, para la Columna de la Independencia. La proposición estaba inspirada, en buena parte, en la escultura de Coatlicue, la impresionante deidad mexica. Abajo del ábaco se desarrollaba la composición escultórica, dividida en dos secciones; la inferior dependía tanto del frente como de la parte postevior de la falda de serpientes entrelazadas de Coatlicue, en tanto que en la sección superior se encontraba el símbolo nacional: el águila con las alas abiertas posando de frente sobre los clásicos nopales, al conjunto hacían fondo unos cactus. En los ángulos aparecían, como en la escul. tura de la diosa, unas cabezas de serpiente de las que pendían colgajos

11 Uno de los descubridores de los valoies estéticos de las artesanías fue el Dr. Atl, q̨uien hacia 1921 en unión de Jorge Enciso, Xavier Guerrero, Adolfo Best Maugard y Roberto Montenegro, organizó una exposición reveladora de las manifestaciones artísticas del pueblo; la exposición dio lugar a la primera publicación de un libro dedicado al tema: Las artes populares en México (1921). 
cúbicos. Los cráneos de la muerte y otros símbolos indígenas no se tomaron en cuenta en el estudio, del cual no se sabe quién fue su autor (figura 7 ). 12

Del legado arquitectónico de las viejas cultuxas indígenas, nada ha causado mayor impacto y unánime aceptación que las construcciones mayas, tanto en los arquitectos del país como del extranjero. Y es que esas obras además de presentar un principio, aunque falso, de bóvedas y arcos y los espacios interiores consiguientes, ofrecen como algo distintivo frente a lo europeo, un original gusto ornamental, presente en los edificios de las distintas zonas arqueológicas. Conocida es la importancia que en un momento determinado se dio en los Estados Unidos a las pirámides del Petén, en las que se vio un antecedente americano de los rascacielos de Nueva York. ${ }^{13}$ Algunos arquitectos manejaron tal idea para fines concretos, como fue el caso de Francisco Mújica, quien en un afán de encontrar las "yaíces" de los Skycraper, calificó de "Neo American Style", a la arquitectura que mostraba en su ornamentación motivos inspirados en las pirámides de Tikal o Uxmal. A propósito de las altas y limpias superficies de los rascacielos, desprovistos de cornisas clásicas, escribió convencido, lo siguiente:

Recientemente ha surgido una nueva tendencia que, rechazando esquemas preconcebidos del estilo clásico y gótico, intenta definir de una manera espontánea una decoración racional y honesta de la estructura (...) No ha sido posible aplicar a los rascacielos las cornisas de proporciones definidas en el pasado. La nueva arquitectura ha debi. do buscar un nuevo elemento que delimitara simplemente la superficie del muro. En virtud de ello, y del hecho que los principales elementos decorativos han sido proyectados sobre grandes superficies, el nuevo estilo recuerda de una manera impresionante la arquitectura precolombina, en especial los palacios y las pirámides de cornisas pequeñas, con magníficas decoraciones en relieve sobre superficies imponentes (..) Me parece justo definir como mesoamericano este nuevo tipo de arquitectura. ${ }^{14}$

12 El dibujo se publicó en el Anuario 1922-1923, de la Sociedad de Arquitectos Mexicanos. La Sociedad se fundó en 1919

13 Vide, Alfred Bossom, Building to the sky: The romance of the Skyscraper, London, The Studio, 1934.

14 Citado por Manfredo Tafuri, "The New Babylon: los gigantes amaxillos y el mito del americanismo", ensayo contenido en La esfera y el laberinto, Barcelona, G. Gili, 1984, pp. 228-29. Francisco Mújica escribió e ilustró un libro en el que expone sus ideas al respecto, Vide, History of the Skyscraper, primera edición, Paris 1929. Segunda, Nuera York, DaCapo Press, 1977 


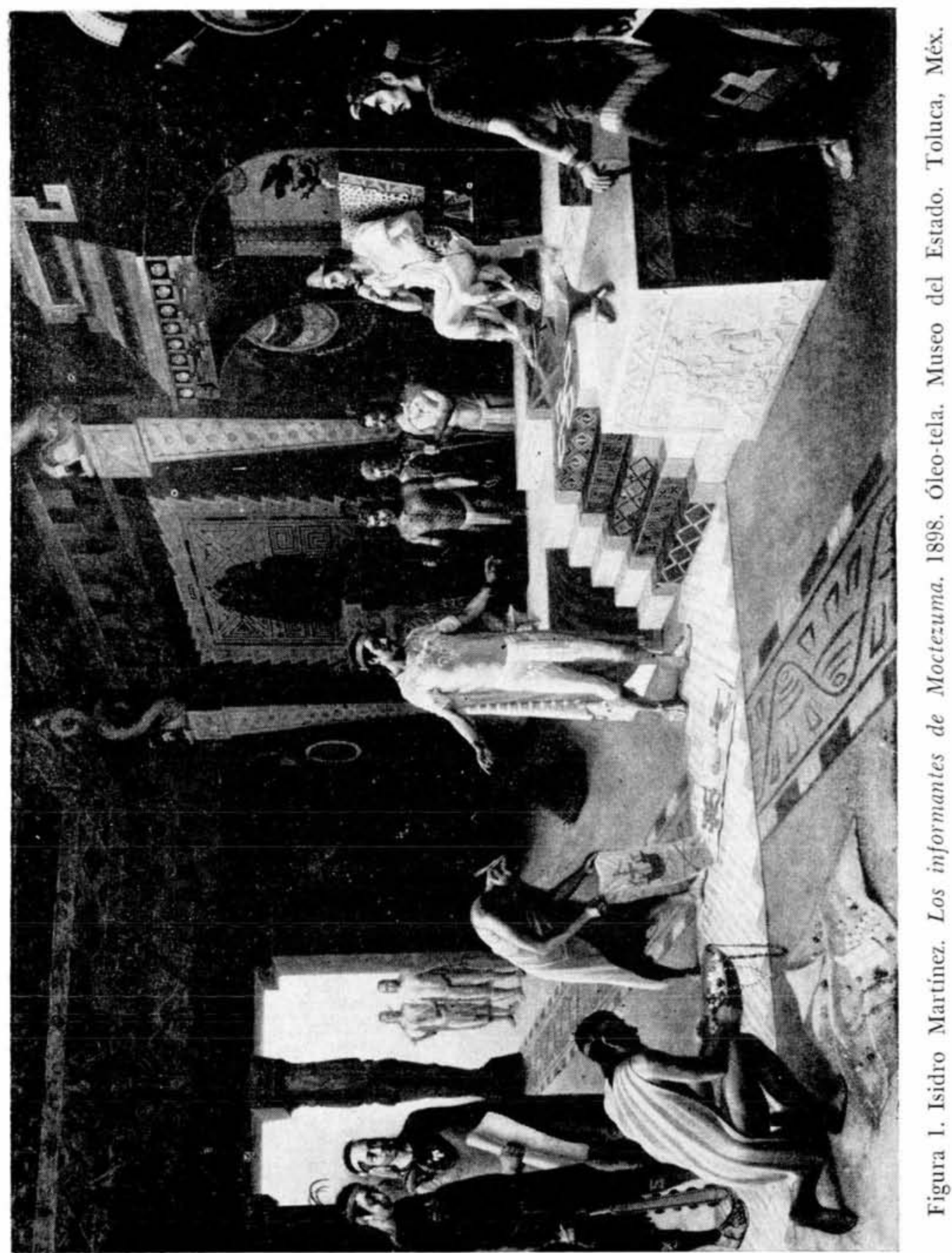


DOI: http://dx.doi.org/10.22201/iie.18703062e.1986.55.1275

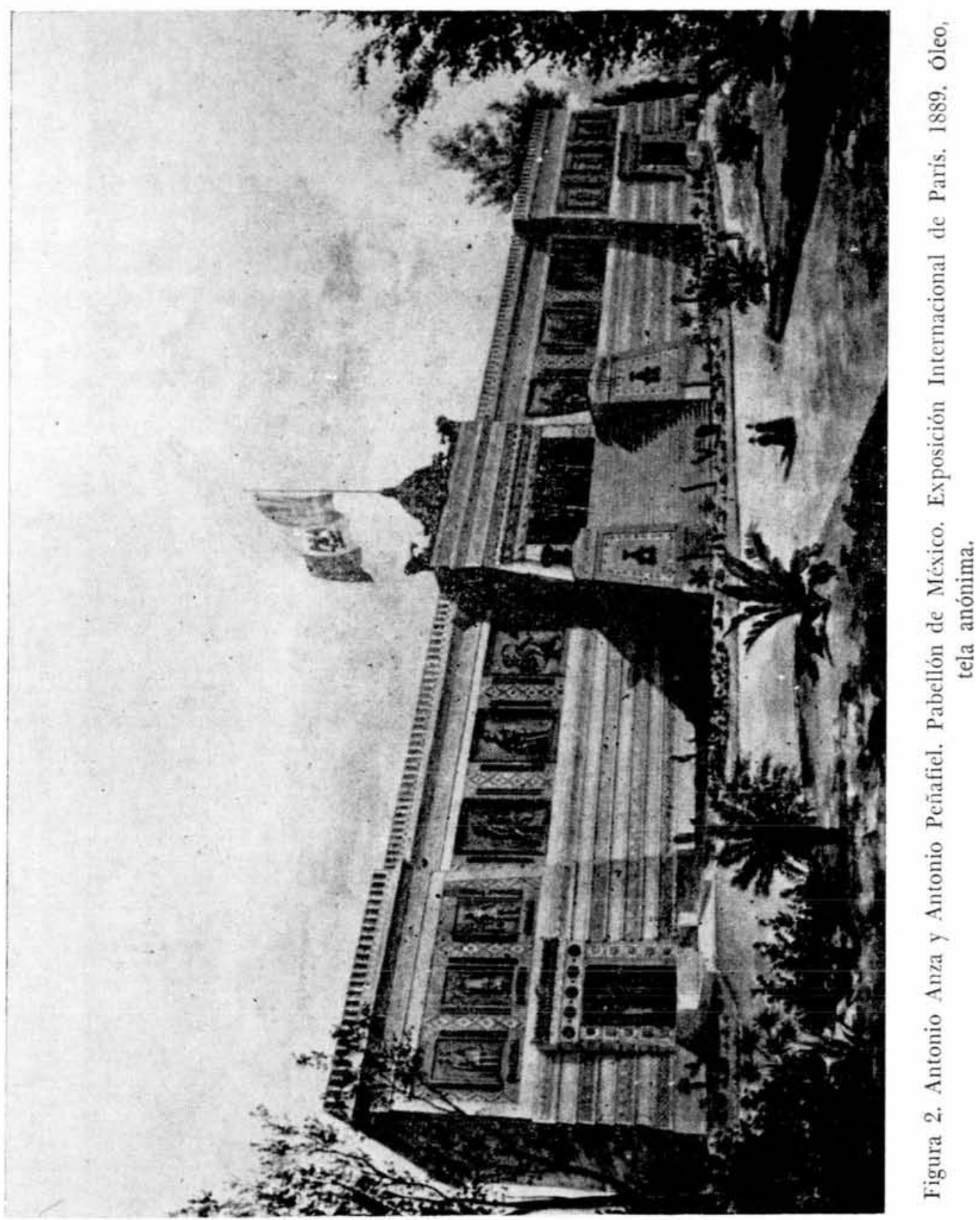


DOI: http://dx.doi.org/10.22201/iie.18703062e.1986.55.1275

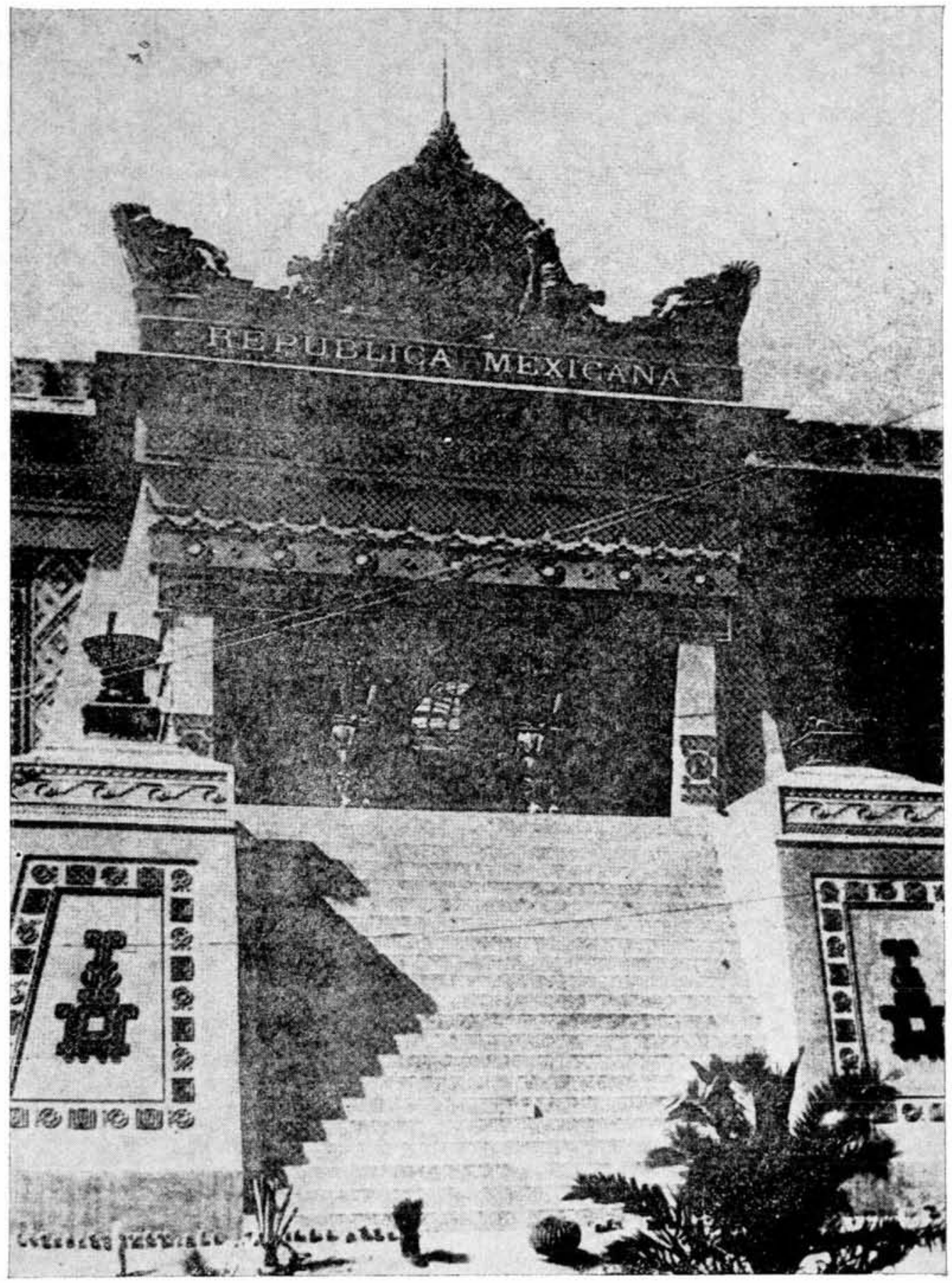

Figura 3. Pabellón de México. Exposición Internacional de París. 1889. Fotografía de la época. 


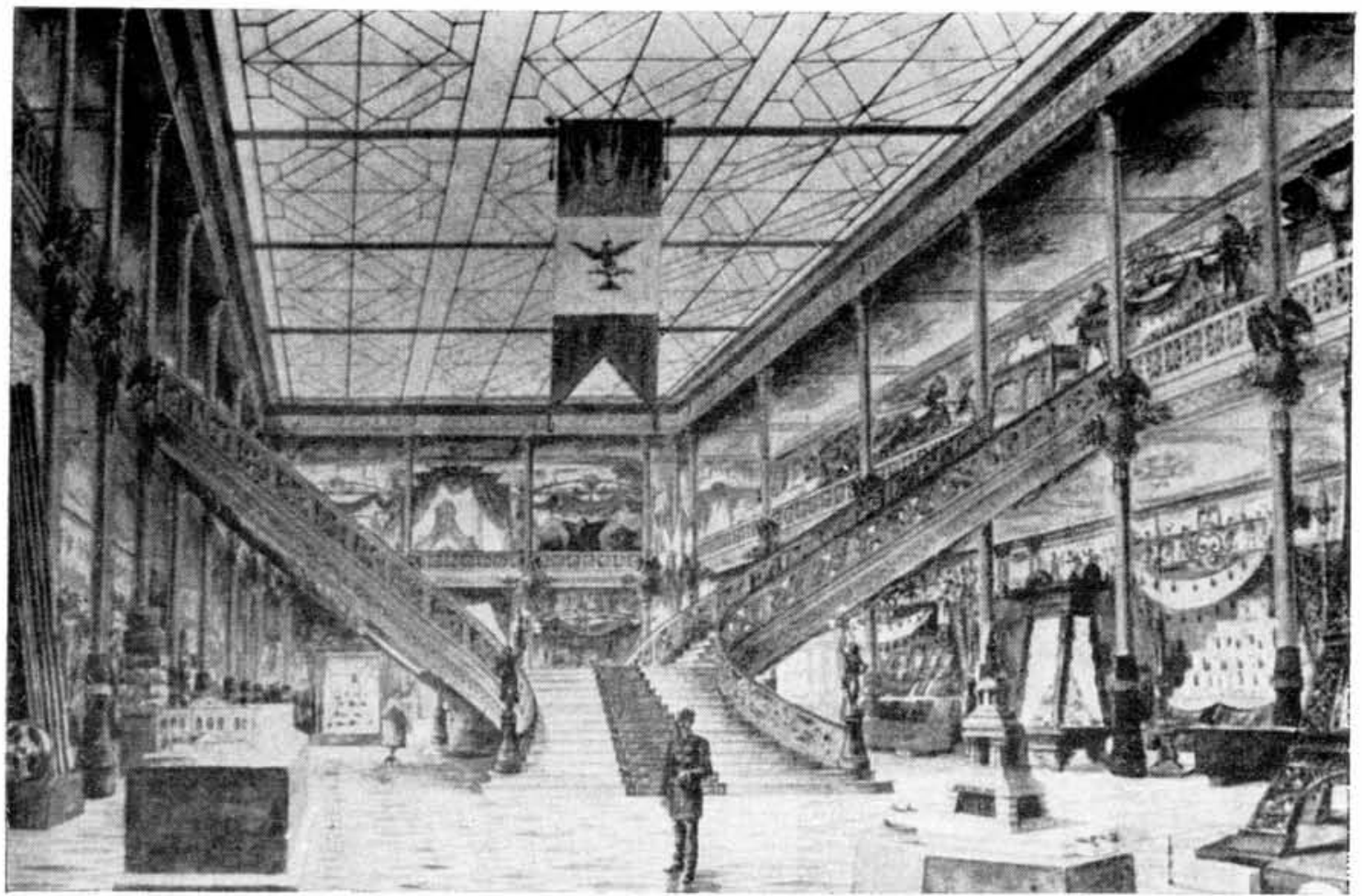

Figura 4. Pabellón de México. Exposición Internacional de Paris. 1889. Interior. Óleo, teìa anónima.

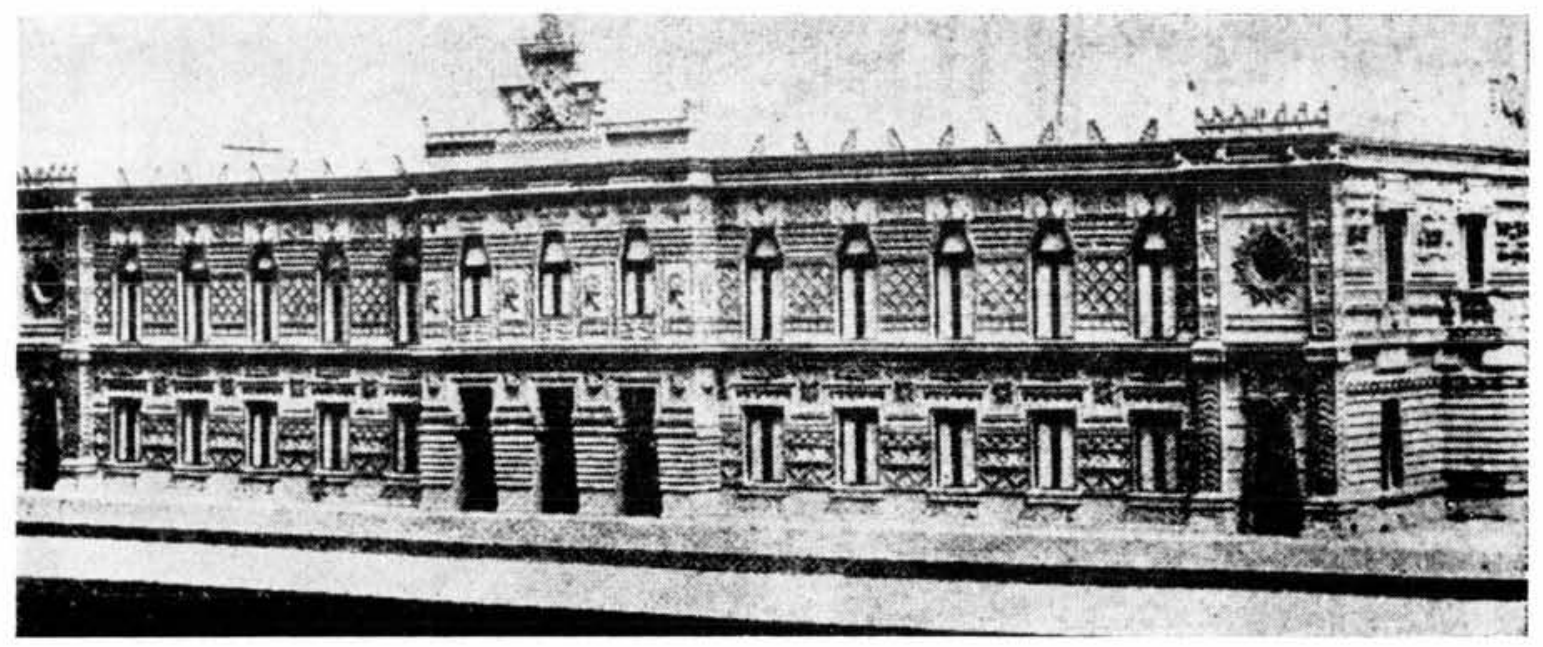

Figura 5. Luis Salazar, Vicente Reyes y J. M. Alva. Proyecto para el Pabellón de México. Exposición Internacional de París. 1889. 
DOI: http://dx.doi.org/10.22201/iie.18703062e.1986.55.1275

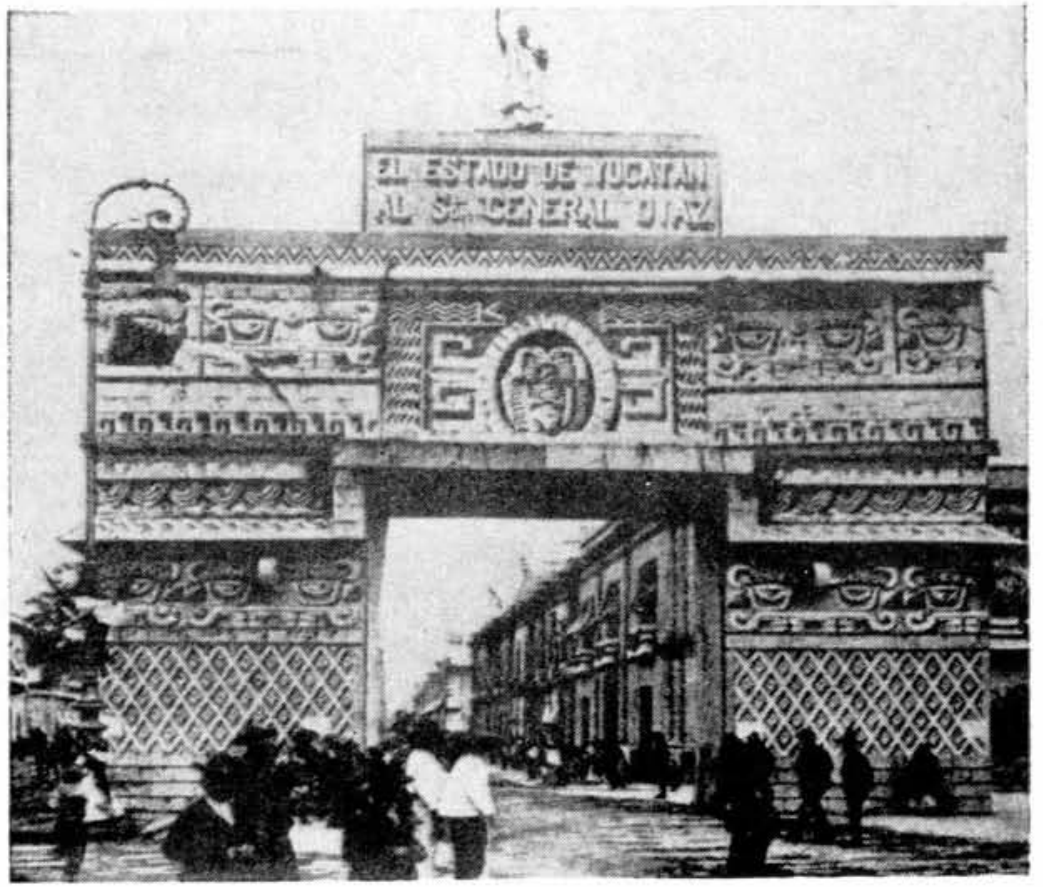

Figura 6. Leopoldo Batres. Puerta maya. México, 1899.

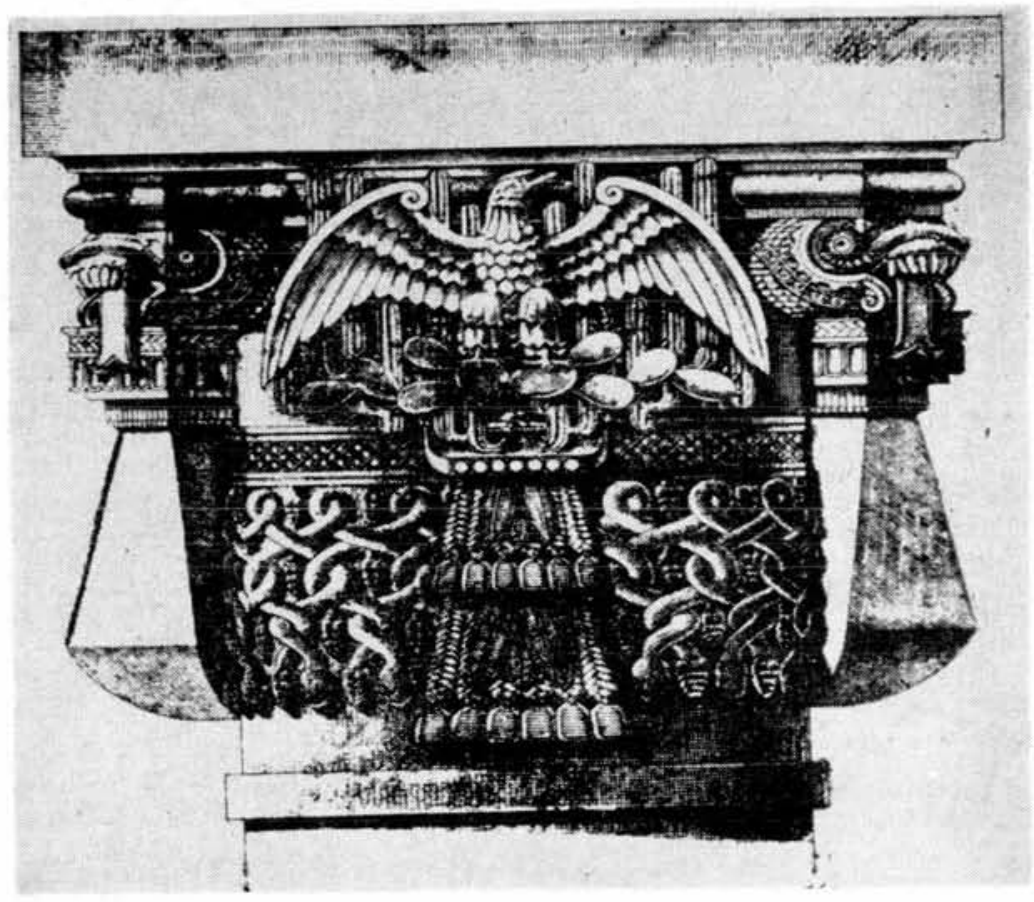

Figura 7. Capitel mexicano. Estudio. 1922. 


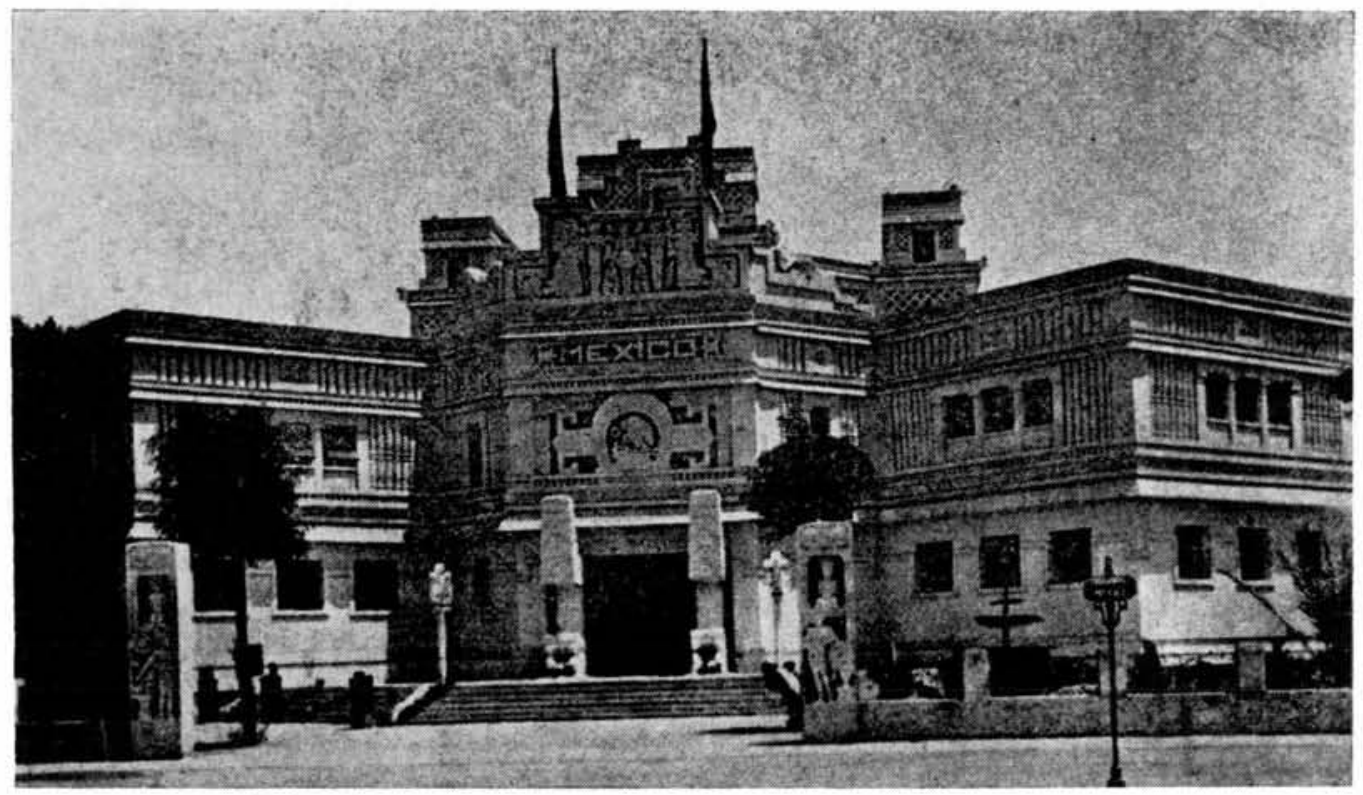

Figura 8. Manuel Amábilis. Pabellón de México. Exposición Ibero-Americana de Sevilla, 1926.

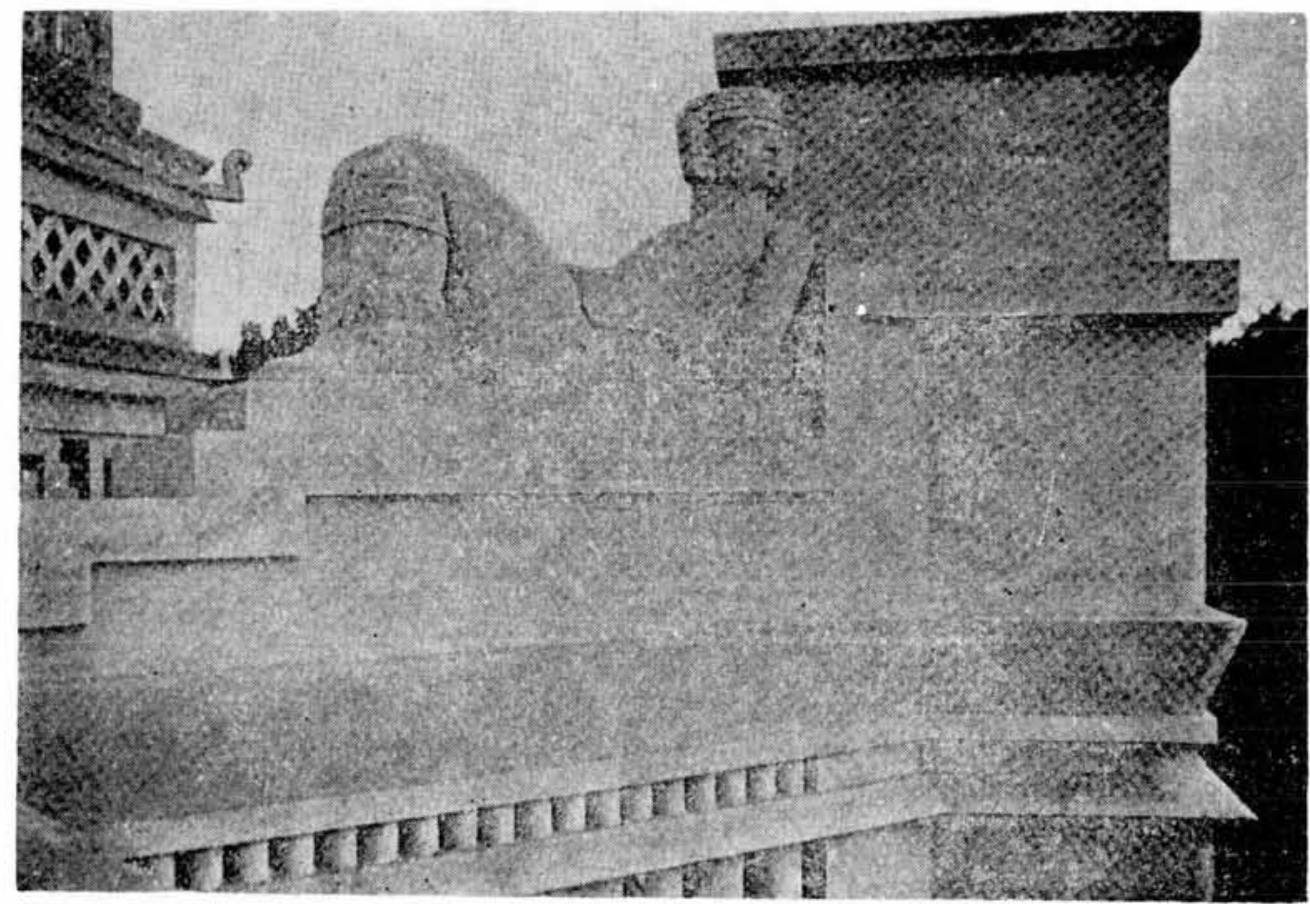

Figura 9. Manuel Amábilis. Pabellón de México. Exposición Ibero-Americana de Sevilla. Detalle con un Chac-Mol. 


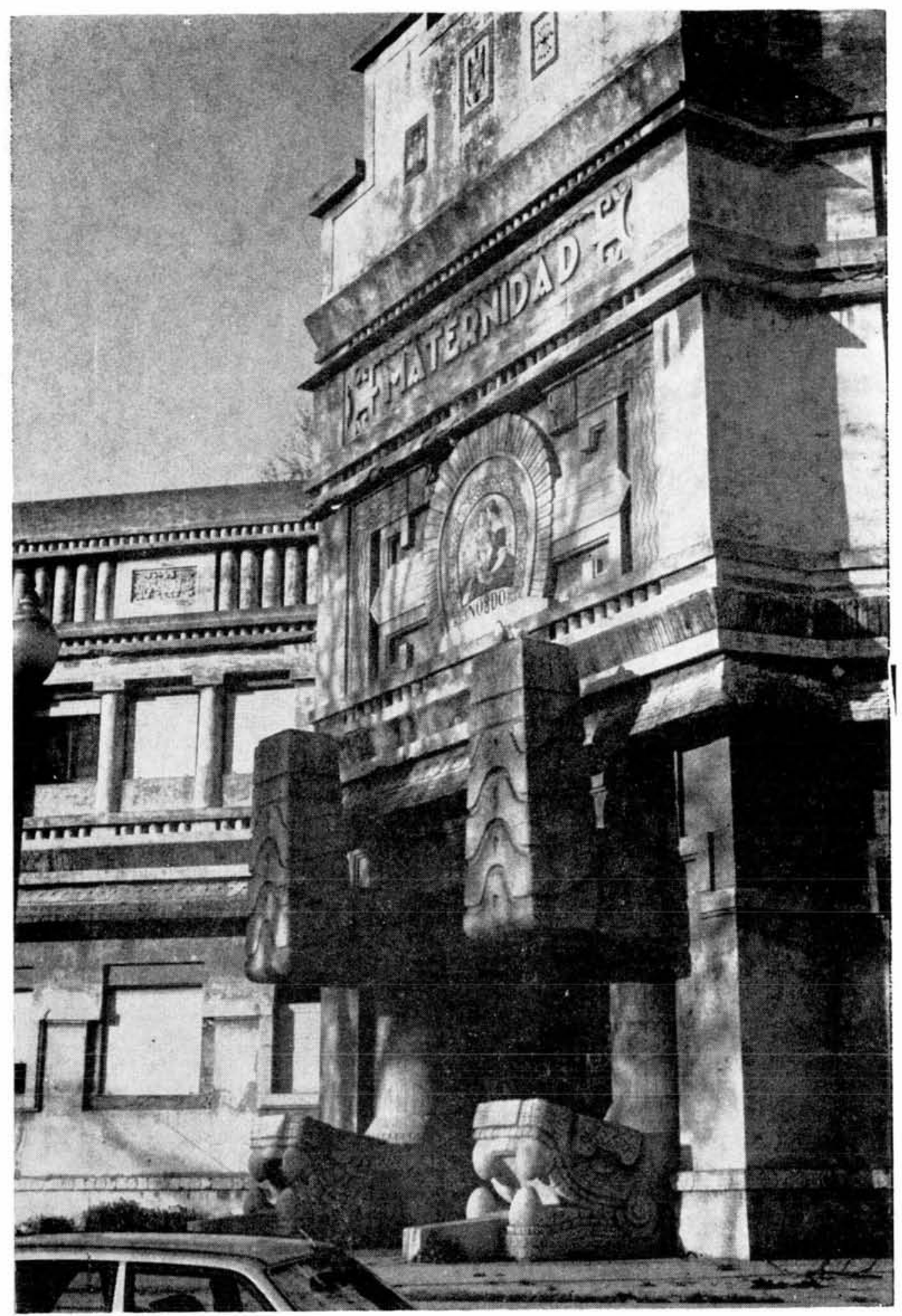

Figura 10. Manuel Amábilis. Pabellón de México. Exposición Ibero-Americana de Sevilla. Detalle de la entrada. 


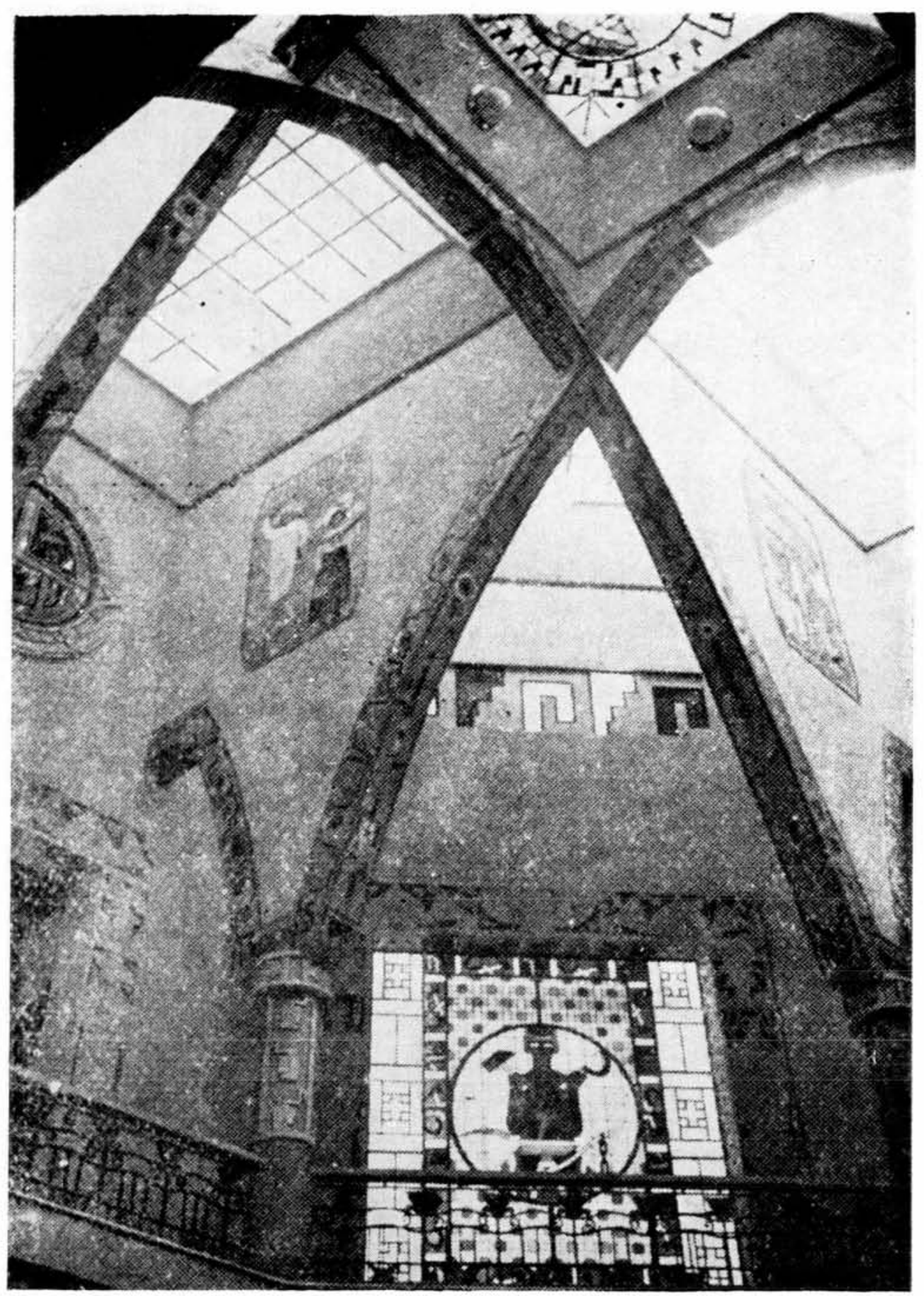

Figura 11. Manuel Amábilis. Pabellón de México. Exposición Ibero-Americana de Sevilla. Detalle del interior. 


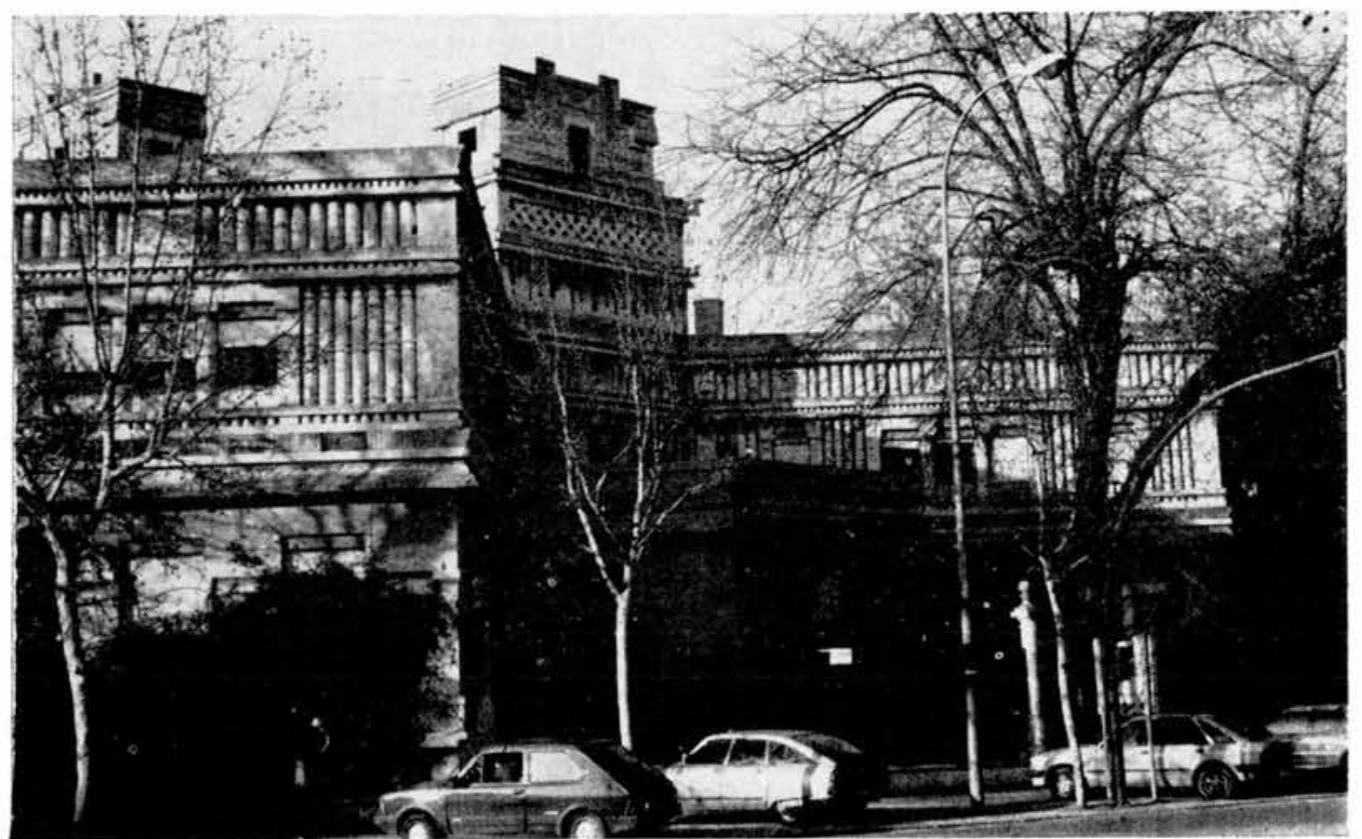

Figura 12. Sevilla, España. El edificio de Amábilis en la actualidad. Foto de Pablo Ferrand.

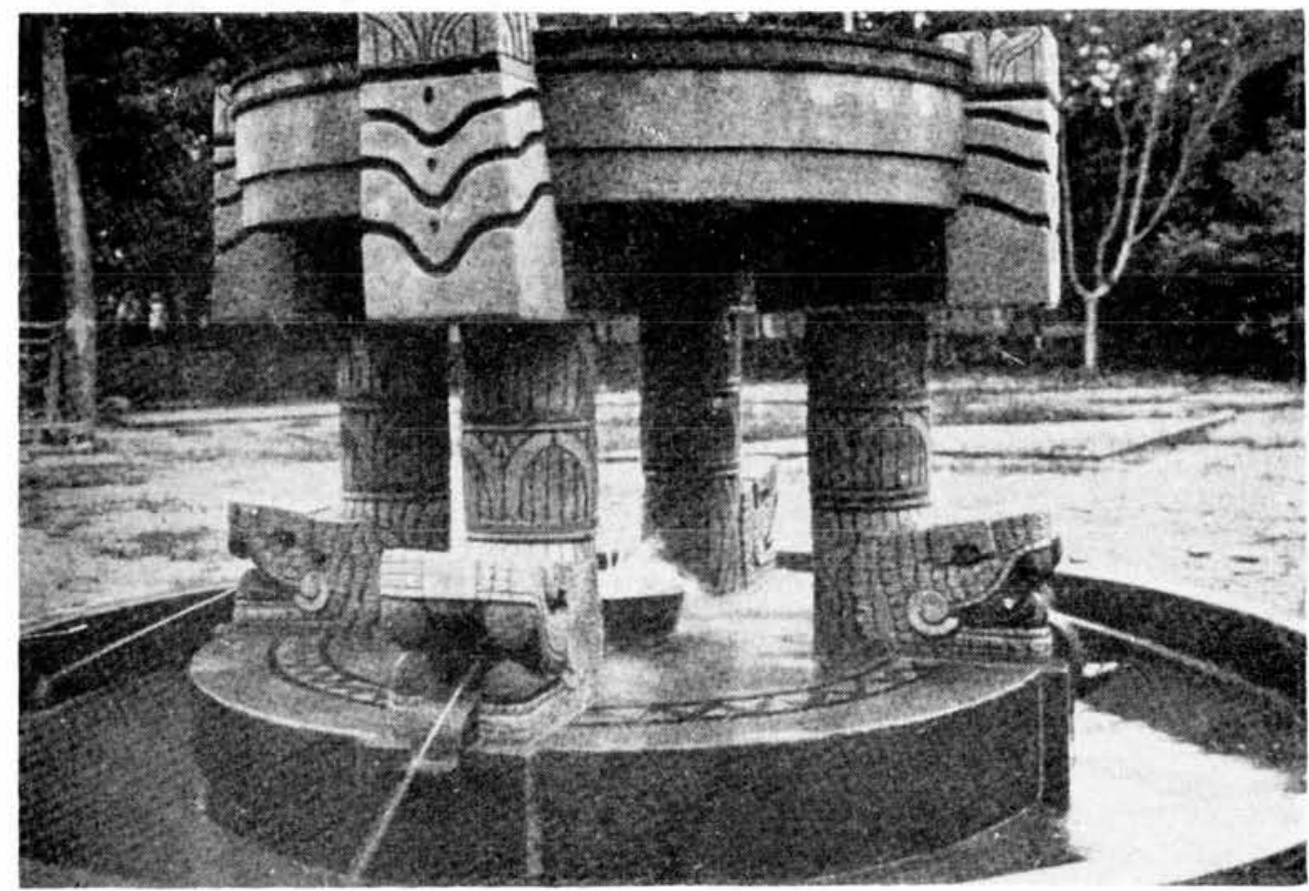

Figura 13. Manuel Amábilis. Pabellón de México. Exposición Ibero-Americana de Sevilla. Fuente. 


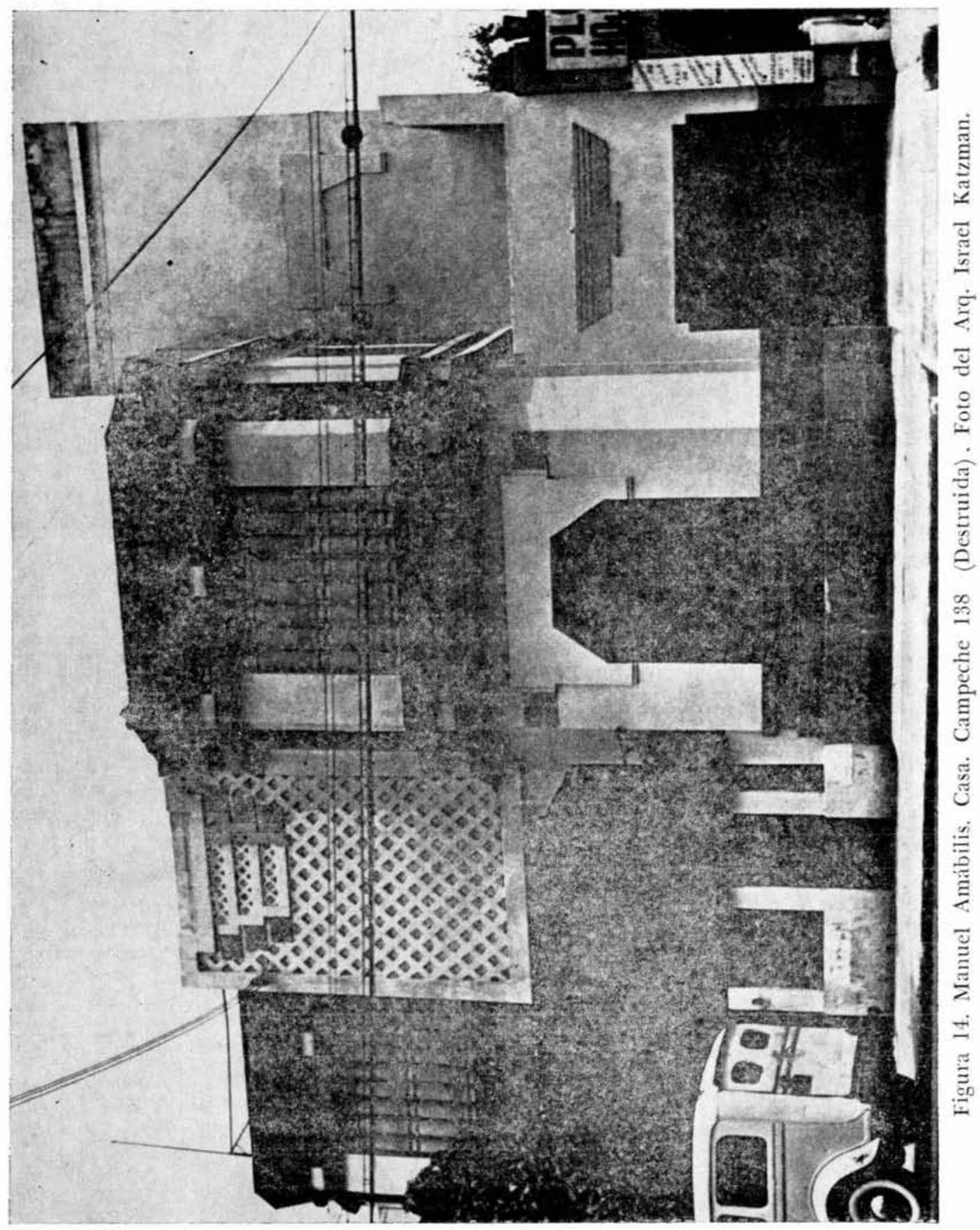


DOI: http://dx.doi.org/10.22201/iie.18703062e.1986.55.1275
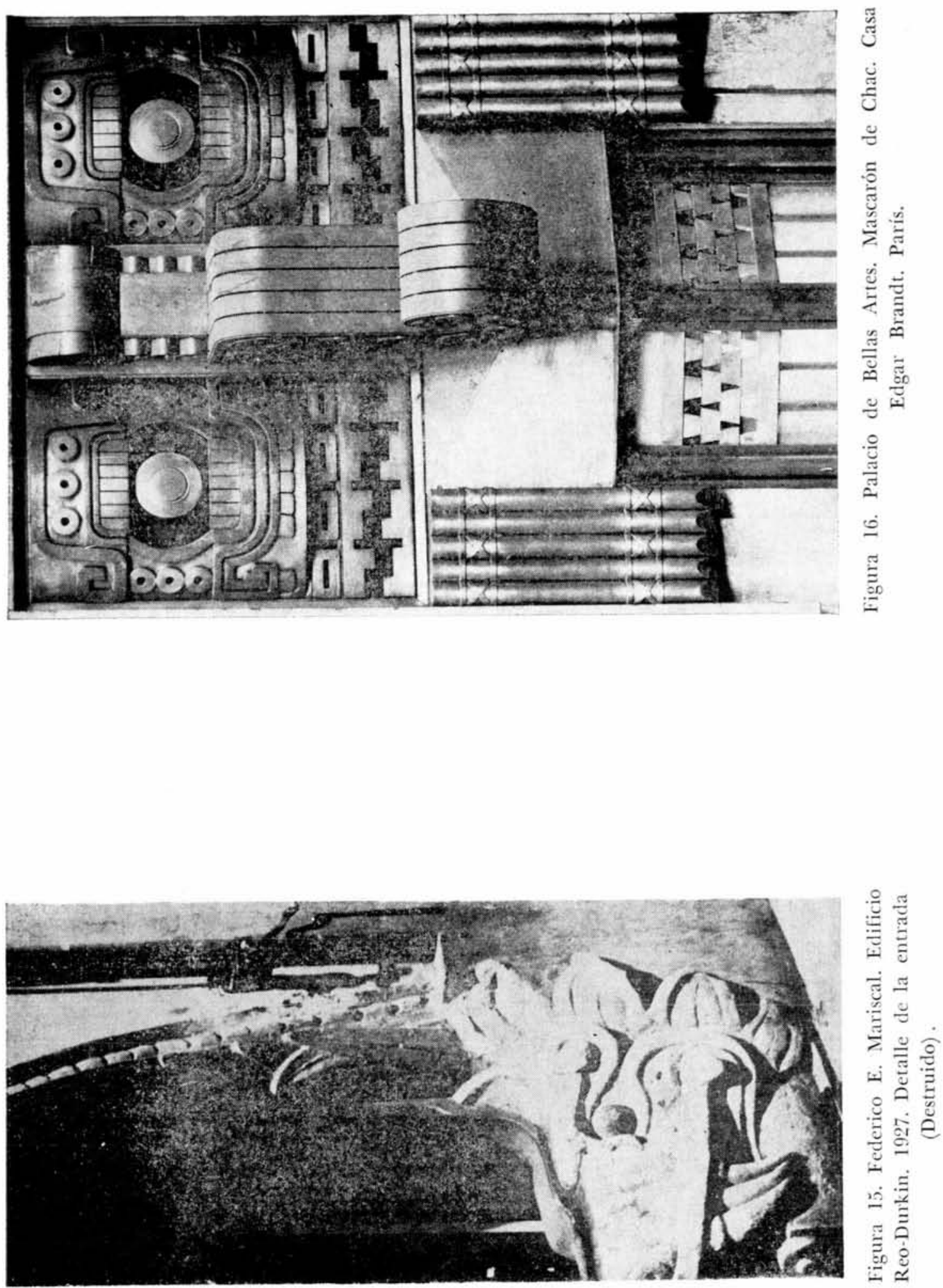


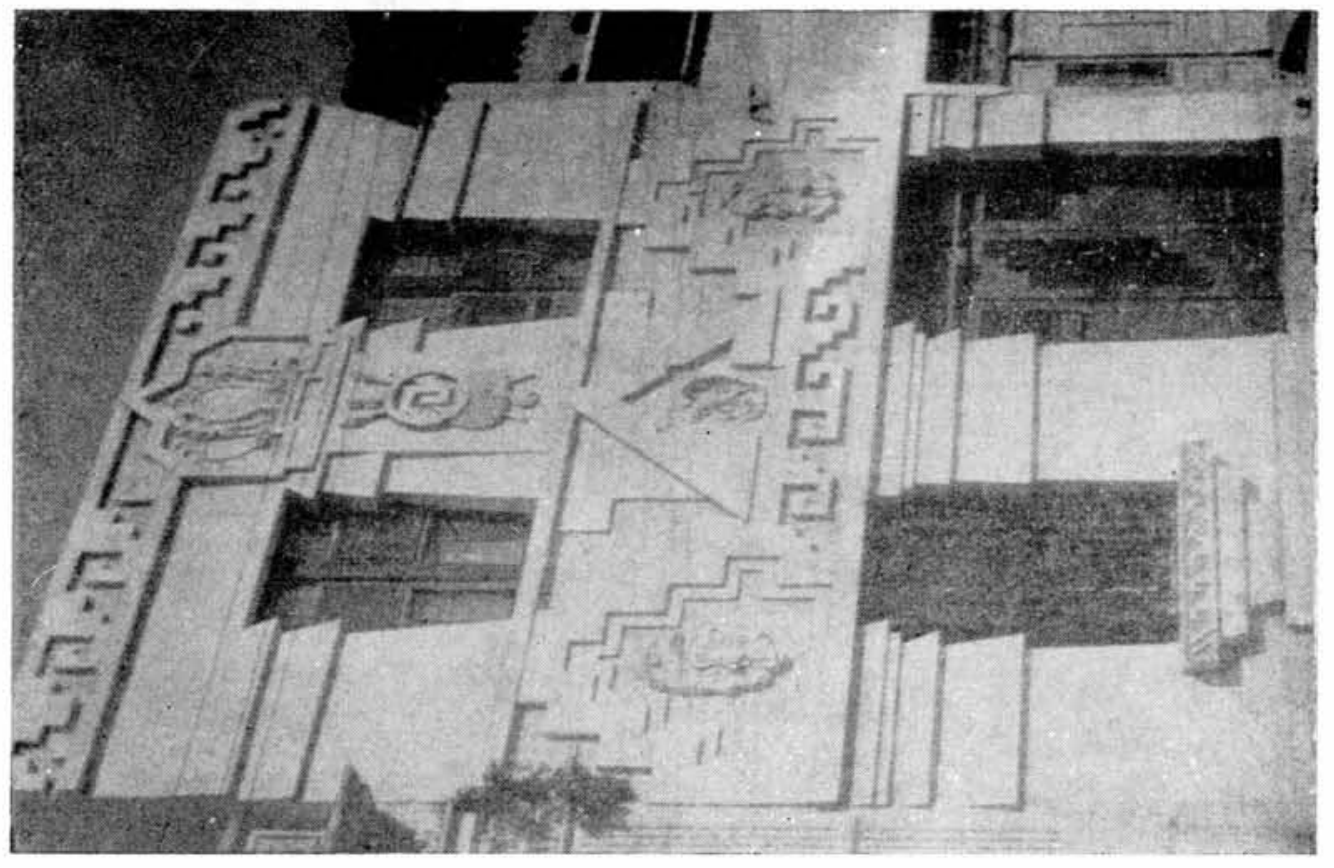

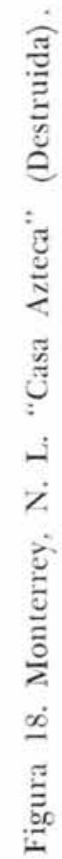

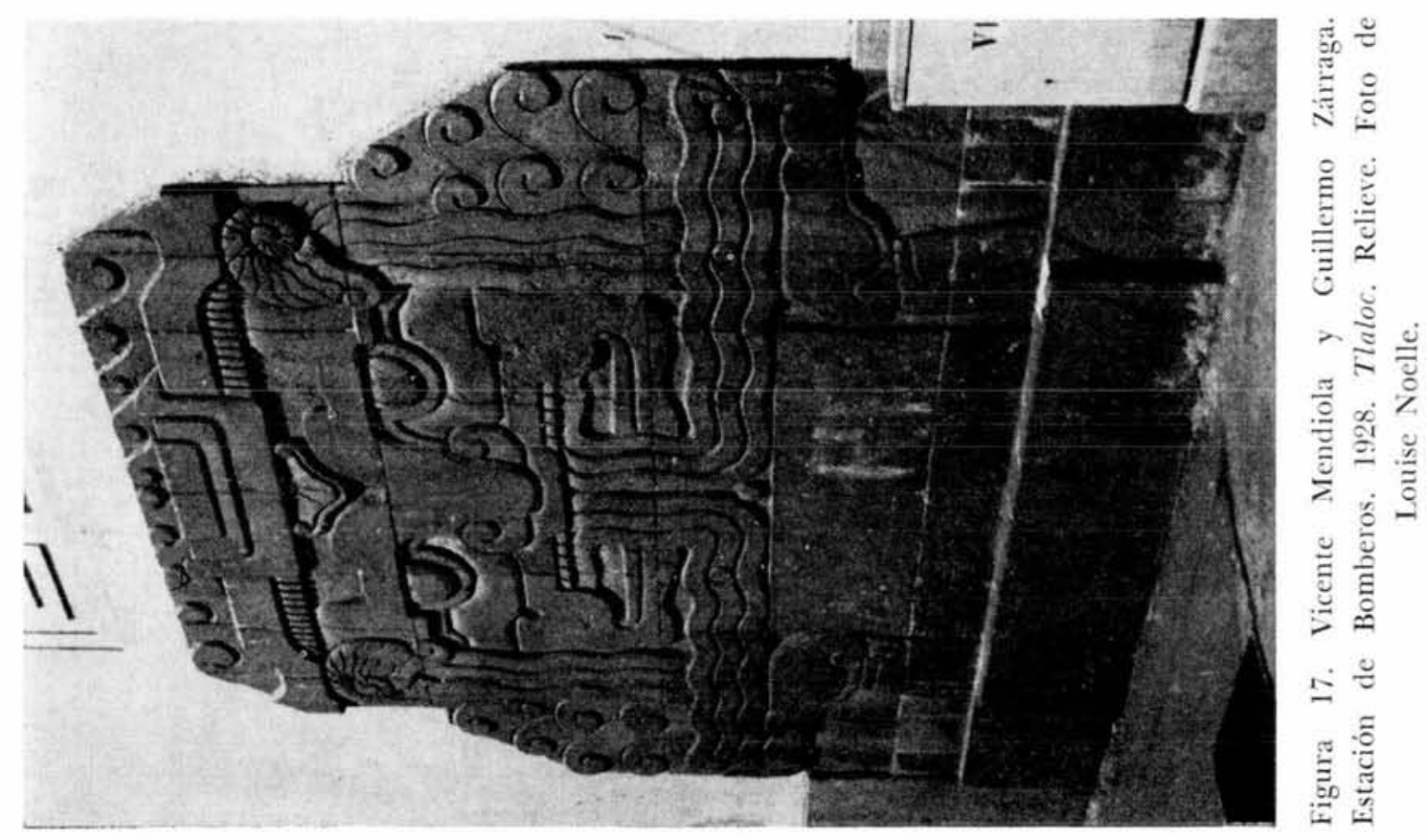




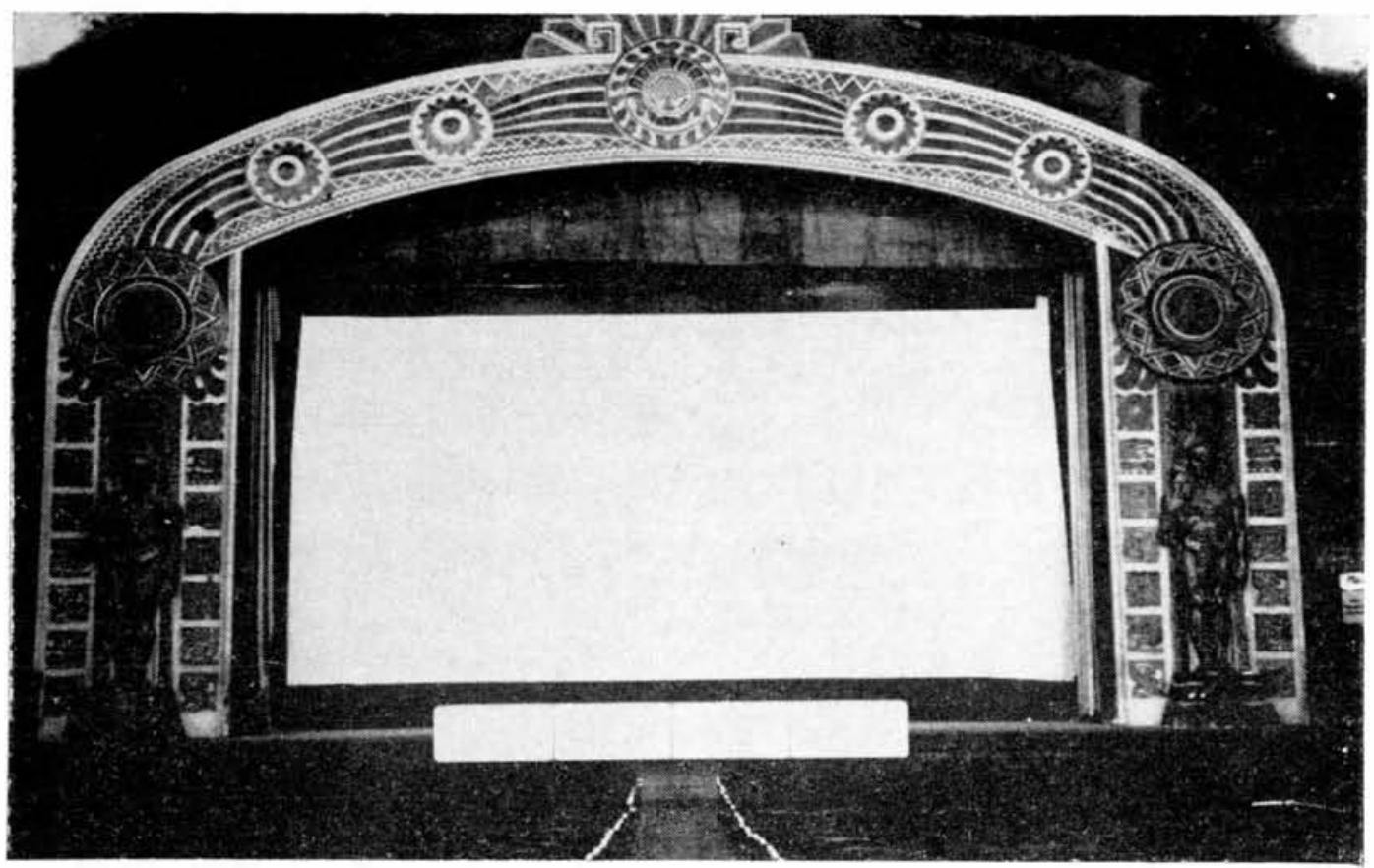

Figura 19. México, D. F. Cine. Interior.

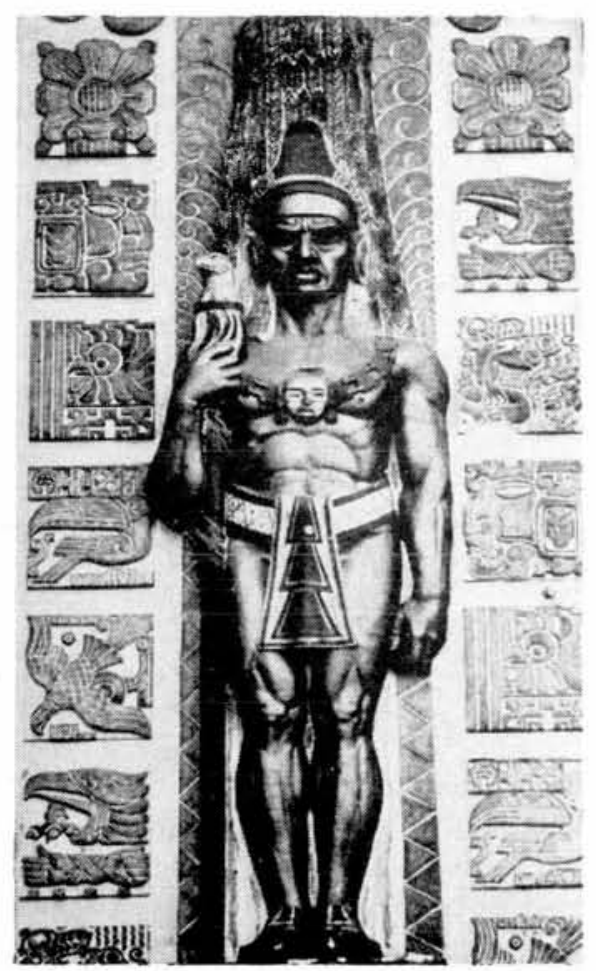

Figura 20. México, D. F. Cine. Escultura. 
DOI: http://dx.doi.org/10.22201/iie.18703062e.1986.55.1275

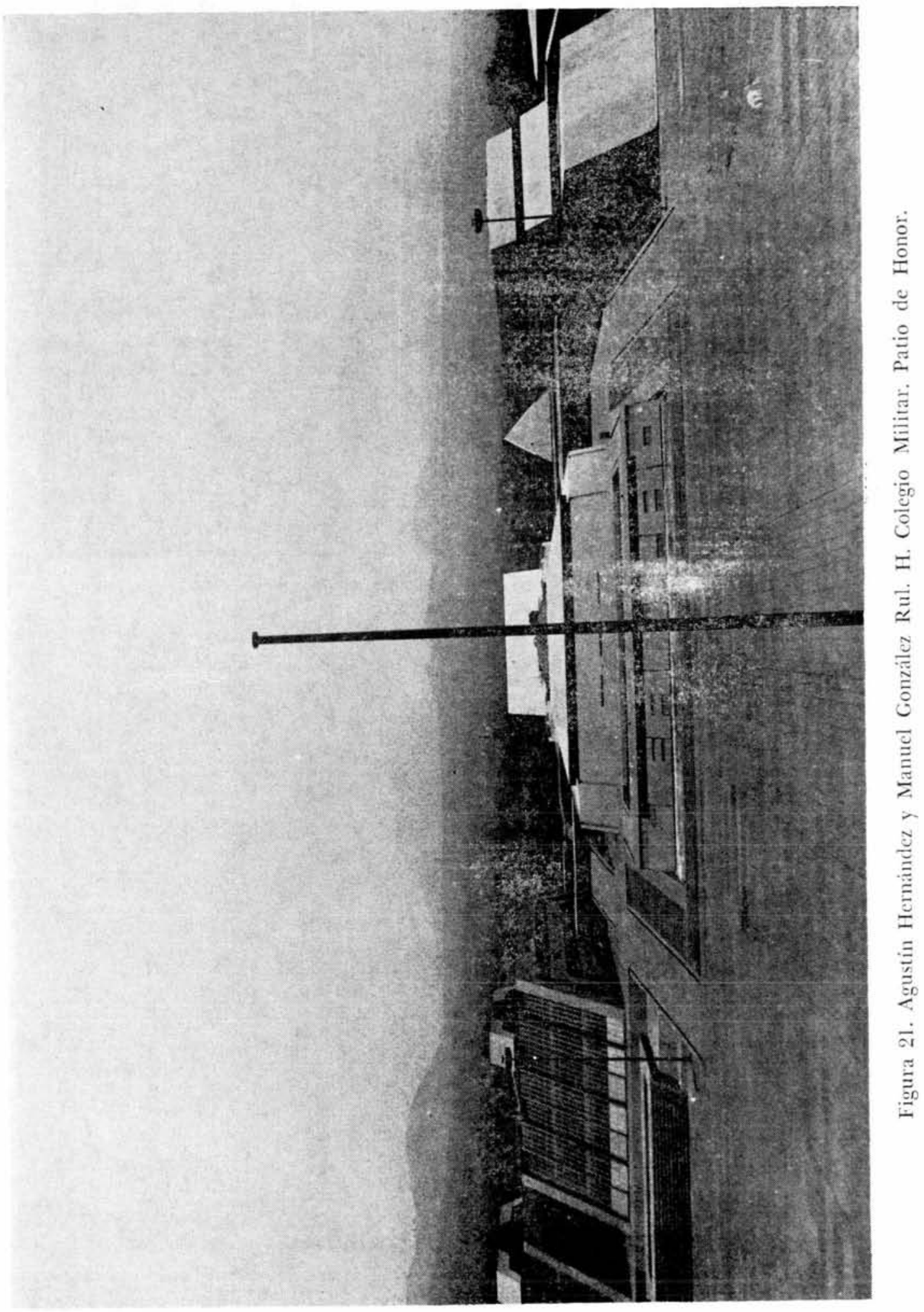


DOI: http://dx.doi.org/10.22201/iie.18703062e.1986.55.1275

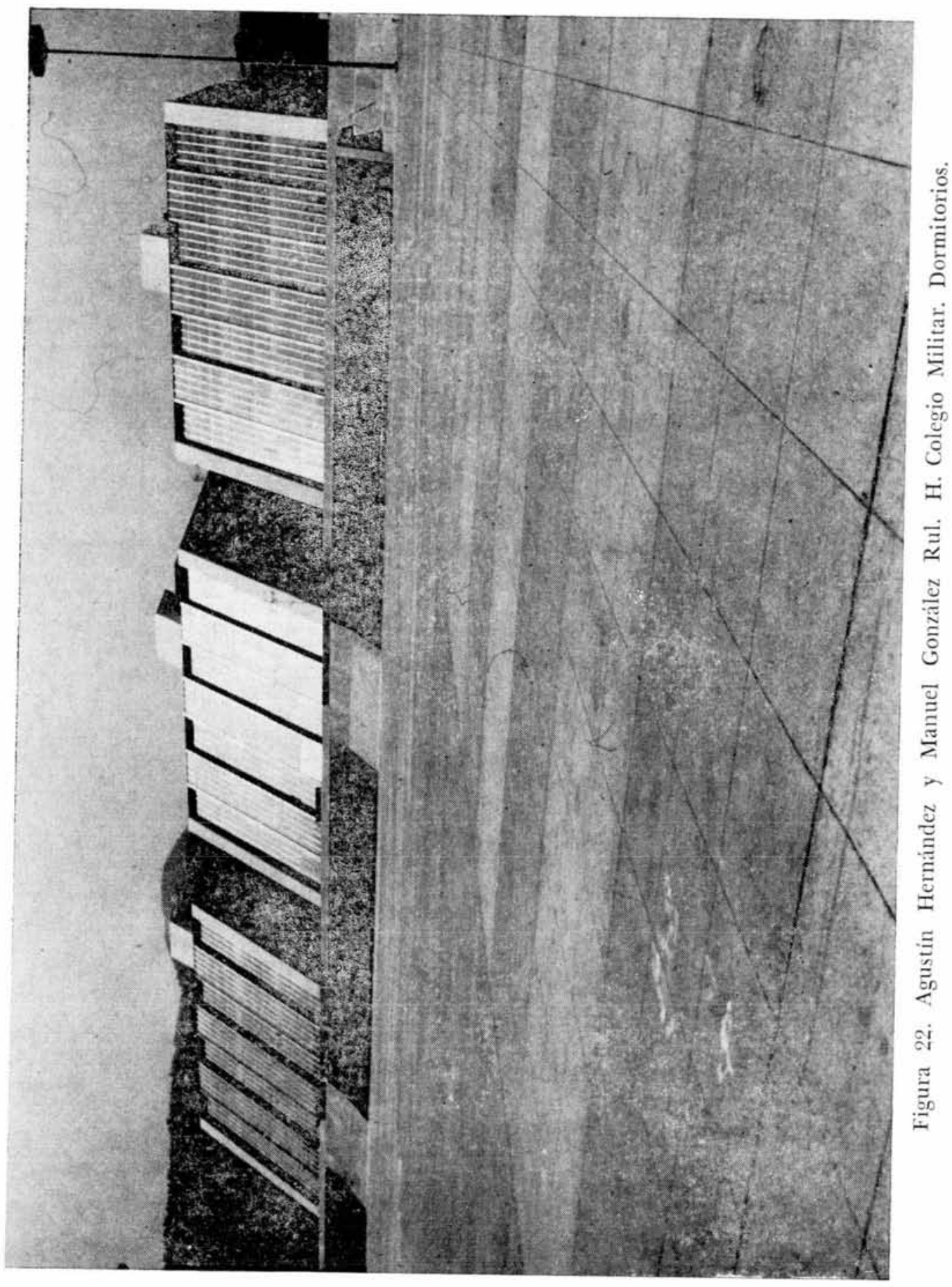




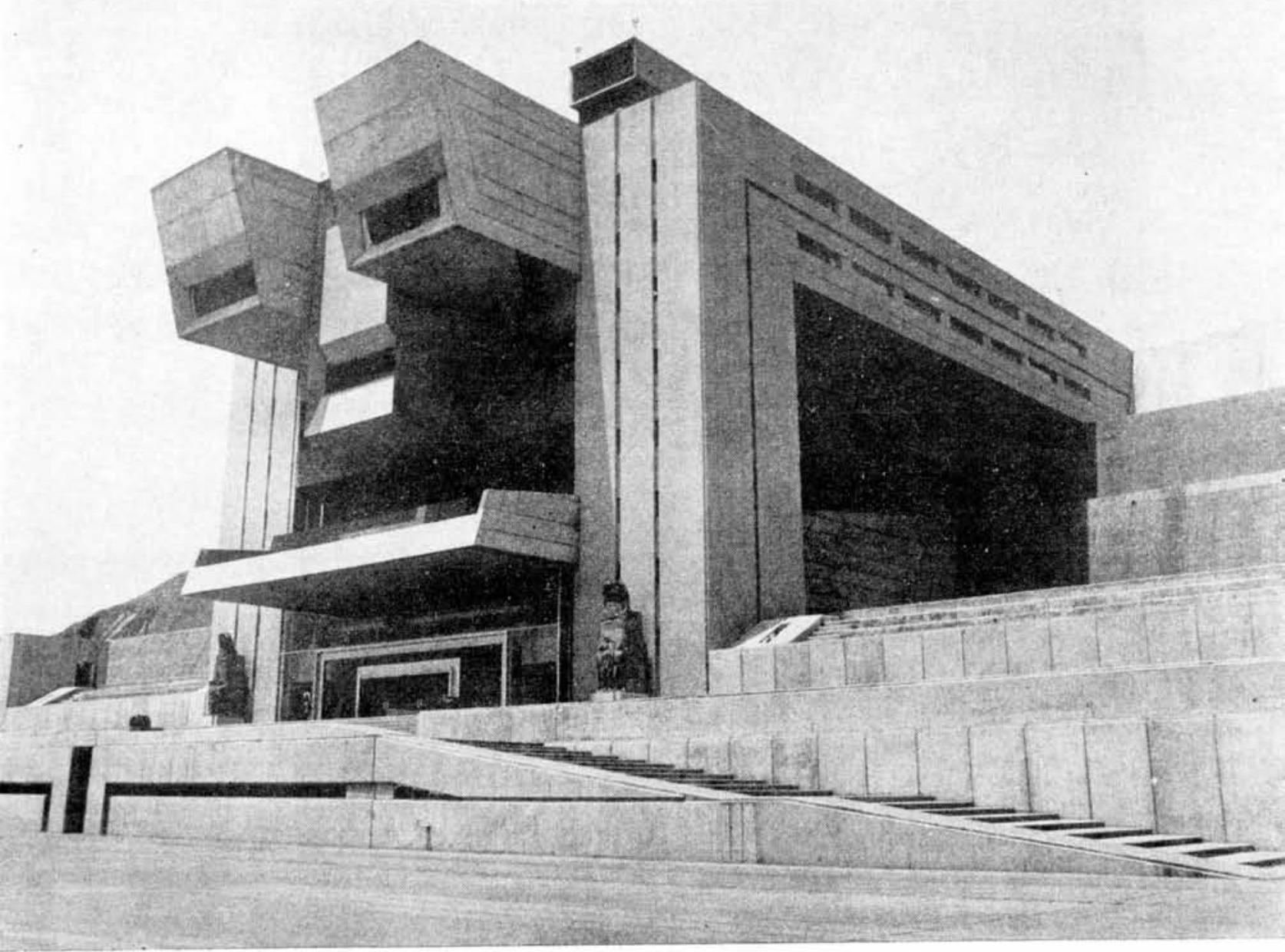

Figura 23. Agustin Hernández y Manuel González Rul. H. Colegio Militar. Edificio de Goíierno. 
No es ésta la ocasión de ocuparse de la presencia de la arquitectura maya en los Estados Unidos, baste recordar que a su influencia no se sustrajo Frank Lloyd Wright, en un buen número de obras yealizadas en la segunda y tercera décadas del siglo, de las cuales quizá los ejemplos máximos sean la Holly Hook House y la Charles Ennie House Tal presencia se mantuvo activa aproximadamente de 1910 a 1940, en construcciones de muy variado carácter e importancia, mas todas deudoras en lo decorativo, de los edificios localizados en Yucatán, El Petén y otras zonas arqueológicas. Bajo tal influencia se construyeton obras espectaculares como el famoso Teatro Maya, de Los Angeles, Calif. (1927), y el no menos interesante de Denver, Co. (1930) . ${ }^{15}$ Robert B. Stacy-Judd fue un arquitecto entregado por completo a recrear la arquitectura maya, preocupado además por la ambientación de los interiores, incluyendo muebles; a él se debió la creación de edificios como iglesias, escuelas, hoteles y residencias mayoides localizadas, en su mayor parte en California. ${ }^{16}$

Como no podía ser menos, el interés por la cultura maya a través de su arquitectura en México no dejó de manifestarse, puesto que encajaba bien dentro del fermento nacionalista de la Revolución que buscaba la identidad del país. A ello contribuyeron, en una forma o en otra, los más eminentes representantes de la vida nacional, como fue el caso del ingeniero Pastor Rouaix, quien en 1919 encargó al arqueólogo Ignacio Marquina, le proyectara un "hall maya" para su residencia. Como se hablaba de modernizar el arte maya para tal efecto, no es ocioso transcribir aquí algunas líneas sobre el proyecto de Marquina:

... la escalera de madera tallada es fiel reproducción de las serpientes de Xochicalco que aun cuando existen en el Estado de Morelos son de indiscutible tipo cultural maya. EI sacerdote que aparece en la vitrina de colores es uno de los que está representado en el relieve de la Cruz de Palenque... El pilar adjunto es una estilización de una de las célebres estelas de Copán. El chaise-longe o diván. . forma un originalísimo mueble idéntico al original que fue hecho en relieve de estuco en uno de los departamentos del templo maya de Palenque.

Para el autor anónimo de esta descripción, dentro del arte antiguo de

15 Una abundante documenatción gráfica sobre el tema se encuentra en el libio de Marjorie I. Ingle The Mayan revival style. Arte Deco mayan fantasy. Salt Lake City, Peregrine Smith Books, 1984. Aun cuando el estudio no convence satisfactoriamente, el libıo es de obligada consulta para quien se interese en el tema.

16 En la obra citada anteriormente se proporcionan noticias sobre la vida y las actividades de Stacy Judd. 
México, el maya era lo máximo en estética, puesto que bien se prestaba, por "su armonía", para modernizarlo, lo cual no sucedía con el "azteca del último periodo" (sic), al que encontraba fatal precisamente por su "falta de armonía". 17

Habria de ser un arquitecto yucateco a quien correspondiera el mérito de construir varios edificios en los que está presente, conscientemente, la herencia del gran arte maya, conciencia adquirida mediante el estudio metódico de los antiguos edificios. El arquitecto en cuestión fue Manuel Amábilis (1886-1966). ${ }^{18}$

En 1928 durante el gobierno del presidente Plutarco Elías Calles, se publicó la convocatoria de un concurso para construir el Pabellón Mexicano en Sevilla, para la Exposición Ibero-Americana. Participaron en el evento veintitrés arquitectos. Como suele acontecer hubo inconformidades en la otorgación del premio, por lo que fue necesario organizar tres veces el concurso, finalmente obtuvo el galardón el proyecto firmado por "Itza", cuyo autor era Manuel Amábilis. En los trabajos presentados figuraban las dos corrientes nacionalistas de la arquitectura: la prehispánica y la colonial. En la primera los proyectos más sobresalientes, todos de franca inspiración maya, correspondían a Alberto Mendoza, Manuel Obregón Escalante, Ignacio Marquina y el citado Manuel Amá. bilis. Entre los colonialistas se encontraban Vicente Mendiola Q, Carlos Obregón Santacilia y Carlos Tarditi, Salvador Vértiz H., Agustín García y también Ignacio Marquina. Un proyecto que dependía aun de lo colo.

17 "E1 arte maya modernizado", en Revista de Revistas, núm. 483, México, agosto 3 de 1919.

18 No obstante la importancia que reviste la obra del arquitecto Manuel Amán bilis Domínguez, no existe estudio alguno de cuanto construyó y de otras actividades no menos importantes a las que entregó su existencia, como el interés que mostró sobre la historia antigua de Yucatán y las teorías que escribió sobre el arte maya El arquitecto Amábilis nació en la ciudad de Mérida, Yuc, donde realizó sus estudios de bachillerato hasta 1906, pasando más tarde a la Escuela Especial de Axquitectura de París donde se graduó en 1912. Al retonar a México durante los años álgidos de la Revolución, colaboró en el gobierno del general Salvador Alvarado, como director de Obras Públicas La primera etapa de su labor como arquitecto se encuentra en una serie de edificios que levantó en Mérida, entre otros el de la Casa del Pueblo; esa valiosa obxa no se conoce y como el resto de cuanto bizo, está en espera de su estudio. Por otra parte, en la Escuela de Arquitectura dependiente de la Universidad Nacional, ocupó la cátedra de teoría de la axquitectura, a la cual renunció cuando se fue a Sevilla en 1928 a construir su famoso pabellón; en la cátedra le siguió su discípulo José Villagrán García "Estuvo ligado con la masonería y se interesó mucho en la teosofía, en la cual llegó a ser un maestro destacado. Fue un escritor prolífico, publicó varios libros y estudios sobre el origen de "Los toltecas o mayas", su singular cultura y el mito de la Atlántida. 
nial a pesar de su aire moderno, fue el que presentaron José Villagrán García, Juan Segura y Vicente Urquiaga. ${ }^{19}$

Manuel Amábilis fue un profundo conocedor de la arquitectura maya de la Península de Yucatán y del río Usumacinta, al estudio de la misma dedicó buenos años de su existencia. Desde 1923 empezó a publicar diversos artículos relacionados con la arqueología de Uxmal y ChichénItzá; ${ }^{20}$ tomaba a la arqueología como punto de partida para el estudio de los edificios, a los cuales analizaba conforme a los conceptos que poseía sobre la arquitectura clásica europea. Sus ideas respecto a las proporciones, sistemas constructivos y razón de ser de la ornamentación indigena, están ampliamente expuestas en su libro La arquitectura precolombina de México (1956).

El edificio proyectado por Amábilis y construido en Sevilla bajo su dirección, está inspirado en la arquitectura maya, que él denominaba erróneamente como tolteca de acuerdo con su época. En el libro descriptivo que escribió a propósito del pabellón, anotó que "todas las estructuras, muros, techo y cubiertas, son de hormigón armado" (figuras 8 y 9). ${ }^{21}$ Copió sobre todo, los temas ornamentales y aun el diseño de los "arcos mayas", "que sostienen la cubierta del patio" (figura 10)..$^{22} \mathrm{El}$ pabellón que hasta la fecha subsiste, tiene dos plantas; "el partido adoptado, según él, consiste en un núcleo central constituido por el hall o patio cubierto, del que irradian los salones de exposición y las demás dependencias". ${ }^{23}$ Colaboraron con Manuel Amábilis en la ornamentación, dos artistas yucatecos, el pintor Víctor $M$ Reyes y el escultor Leopoldo Tommasi López.

El atractivo máximo del edificio está concentrado en la ornamentación exterior del mismo. Motivos tomados de las construcciones de diferentes zonas arqueológicas fueron utilizados por Manuel Amábilis para enriquecer con exceso su obra; así, por ejemplo, las pilastras, con las enormes serpientes del Templo de los Tigres, del juego de pelota de Chichén-Itzá, se copiaron para la puerta del pabellón (figura 11). Relieves inspirados en los de Palenque alternan con mascarones, grecas

19 Vide, Israel Katzman, Arquitectura contemporänea mexicana, Iảmina 30, México, INAH, 1963, pp. 82-83. 1923.

20 Están insextos en varios números de la revista El Agricultor, Mérida, Yuc.

21 Manuel Amábilis, El Pabellón de México en la Exposición Ibero-Americana de Sevilla, México, 1929, p. 16.

22 Idem, p. 43 .

23 Idem, p. 16. 
y narices del dios Chac; los clásicos junquillos atados, del estilo puuc, cubren frisos y secciones de muros, como se encuentran en el Palacio de Zayil. Para la parte superior de la portada del edificio, en los extremos, Leopoldo Tommasi López labró dos esculturas semejantes a la del Chac Mool del Templo de los Tigres en Chichén-Itzá (figura 12). El tipo de serpientes del Templo de los Tigres a Manuel Amábilis le parecía inmejorable como sostén, pues lo empleó también en la fuente que construyó en el jardín que rodea al pabellón (figura 13) ,24

El interior del pabellón era todo un espectáculo por lo que contenía en su decoración y muebles. Relieves en estuco policromados cubrían algunas partes de los muros, los motivos eran de lo más variado y pintoresco, desde nopaleras hasta los imprescindibles diseños tomados del arfe maya, todo hecho por Tommasi López. En cuanto a las pinturas y vitrales de Víctor M. Reyes, quien se consideraba seguidor de Diego Rivera, los temas que ejecutó fueron múltiples: grecas, glifos, flores y frutos, tipos indígenas de México y, no faltaron, las artesanías. Bajo la dirección del propio Amábilis se construyeron los "muebles mayas", para lograr un ambiente apropiado. ${ }^{25}$

Manuel Amábilis fue un entusiasta admirador de la arquitectura maya, pero también era un convencido seguidor del nacionalismo que despertó la Revolución; producto de ambas cosas fue su edificio para la Exposición Iberoamericana en Sevilla. A propósito de encontrar una identidad propia mediante el arte, escribió lo siguiente: “... al tratar de establecer las bases del surgimiento de un Arte Mexicano, era primordial, indispensable, dotarlo de un alma, de un espíritu, que debería ser el de la Nación Mexicana; porque poseyéndolo, nuestro Arte expre saría siempre lo más noble, lo más elevado que guía a la Nación..."; ese espíritu se encontraba para él, en el legado cultural de los antiguos pueblos indígenas. ${ }^{26}$

No fue, por cierto, el edificio sevillano el primero que Manuel Amábilis construyera bajo la influencia de la arquitectura maya. Hacia 1922

24 Años más tarde en la ciudad de México hizo una xéplica de la fuente, misma que estuvo situada hasta su destrucción en la Glorieta Riviera.

25 En un número especial de la revista madrileña La Esfera (1929), dedicado a México con motivo de su presencia en la exposición sevillana, se reproduce mediante una fotografía el interior del hall con los muebles diseñados por Amábilis. Dentro de la corriente indigenisia del nacionalismo fue común el empleo de muebles mayas, mixtecos y aztecas. En el antiguo recinto de la Cámara de Diputados del Estado de Morelos, sita en el Palacio de Cortés, tanto las mesas como las sillas labradas en madera eran de "cstilo azteca".

26 Op cit., p. 23 
edificó en Mérida, la Casa del Pueblo, obra de dos niveles con plantas en forma de $U$, en la que aparecen ya las columnas serpentiformes de Chichén-Itzá, "arcos mayas", réplicas del Chac Mool así como grecas y los junquillos de la ornamentación Puuc. De él se puede decir que fue un seguidor fuera de tiempo de los constructores mayas, teniendo en cuenta otras obras que realizó, como la casa para el señor Negib Simón.

Dicha residencia edificada en la ciudad de México, en su estructura y construcción, obedecía a los lineamientos operantes de la arquitectura mexicana de la época, el concreto y el ladrillo fueron los materiales empleados; según Israel Katzman fue construida en 1942. ${ }^{27}$ Lo singular del edificio estaba por el lado de la ornamentación, sobre todo la del exterior (figura 14). Los cerramientos para puertas y ventanas interiores dependían del diseño de "arco maya". En la portada abundaban las cornisas, las serpientes y los imprescindibles junquillos atados; no faltaban los relieves, labrados en piedra, de tipo palencano. Por primera vez Amábilis empleó aquí una celosía aparente para cubrix un muro, para ello copió el friso del edificio oriental del cuadrángulo de las monjas en Uxmal. La ornamentación interior era pintoresca; como el propietario era de origen árabe, la estancia comedor se arregló con labores en yeso al estilo mudéjar, mas como no podía faltar lo maya, así fue on namentada la sala principal incluyendo los muebles. ${ }^{23}$

Manuel Amábilis construyó un edificio para un centro de fiestas llamado "Teocali 'Super Club". El repertorio formal de origen arqueológico del que tan buen partido sabía sacar, daba carácter a la obra en el exterior. Una escalinata permitía el acceso, la puerta estaba flanqueada por grandes columnas con cuerpo de serpiente; los muros ligeramente cortados en talud; no faltaban, por supuesto, las "cornisas mayas", los relieves, las grecas y los junquillos. El interior debió ser interesante en la solución dada al amplio salón de espectáculos. ${ }^{29}$ No existe información de otras obras semejantes realizadas por Amábilis; mas me parece

27 Vide, op. cit., p. 84 .

$28 \mathrm{EI}$ edificio fue destruido innecesariamentc en 1983, para convertir el terreno en un lote de estacionamiento de autos. Estuvo ubicado en la calle de Campeche 138. La fotografía que aquí se xeproduce la debo a la gentileza del arquitecto Israel Katzman, a quien manifiesto mi agradecimiento

29 Esta obra debio construirse hacia mediados de la década de los años treinta. No hay mayores noticias sobre la misma, salvo una fotogiafía; no existe xegistro de la fecha de su destrucción. Según el arquitecto Mauxicio Gómez Mayorga, participaron en la edificación los atquitectos Fennando del $R$ Torres, Eduardo $\mathrm{J}$. Whiting $\mathrm{y}$ Fernando Belaúnde Texry entones radicado en México. 
oportuno señalar que en los cuatro ejemplos que aquí se han presentado, él ya había agotado prácticamente los xecursos decorativos de que disponía para alcanzar una arquitectura nacional de raigambre indígena, conforme a una preocupación latente en algunos mexicanos; de más está decir que felizmente no tuvo seguidores.

Para concluir con el arquitecto Manuel Amábilis, he de agregar que se mantuvo firme en sus convicciones estético-nacionalistas, ante las nuevas corrientes de la arquitectura, por lo tanto no comprendió el significado trascendente de Le Corbusier, al que censuró sin entenderlo pues por principio de cuentas él se declaraba un tradicionalista; criticó al funcionalismo en medio de incongrencias, en la conferencia, que dictó dentro del importante ciclo de Pláticas que organizó en 1933, La Sociedad de Arquitectos Mexicanos, tendientes a aclarar la posición de la arquitectura ante el funcionalismo. ${ }^{30}$

Contemporáneo de Amábilis fue el arquitecto Federico E Mariscal (1881-1969), un exponente destacado del eclecticismo en la arquitectura mexicana de las primeras décadas del siglo; dentro de esas tendencias quedaron incluidas las viejas culturas deI país. Hacia 1927 Mariscal realizó un viaje de estudios a la península yucateca; tal viaje le resultó benéfico por los descubrimientos que para sí mismo hizo y los consiguientes estudios que efectuó sobre algunos edificios mediantes una serie de levantamientos y análisis, ${ }^{31}$ Tan convencido quedó de lo que aún ofrecía a los arquitectos el arte maya, que recomendó la conveniencia de que los estudiantes de la Escuela de Arquitectura fuesen por lo menos una vez a Yucatán para aprovechar las lecciones que se podían tomar de las viejas construcciones; así escribió que "... se debe resolver de manera definitiva hasta qué punto pueden aprovecharse esas notables ruinas, en la creación de una arquitectura americana o nacional, en nuestros días" 32

En la práctica constructiva de Federico E. Mariscal, la influencia de

30 Vide, Pláticas sobre arquitectura, México, Sociedad de Arquitectos Mexicanos, 1934, pp. 3.11.

31 Como contribución de México al XXIII Congreso de Americanistas, Mariscal los publicó en el libro Estudio arquitectónico de las ruinas mayas Yucatán y Campeche, México, SEP, 1928.

320 . cit, p. 3. Ahí mismo escribió lo siguiente sobre Amábilis a quien debió conocer en ocasión de su viaje al sureste: “... y la reconstyucción cuidadosa de 'Tas tortugas' de Uxmal, del arquitecto yucateco Manuel Amábilis quien, además, en varias conferencias ha expuesto un estudio arquitectónico muy interesante de lo que él llama 'órdenes Mayas', que quizá podríamos llamar más bien 'trazados reguladores' en la arquitectura maya". 
lás culturas indígenas no tardó en manifestarse; así en el Edificio Durkin que en 1927 construyó para la exhibición de autos y camiones, la amplia curva del vano de la puerta central se desprendía del piso mediante dos grandes cabezas de serpientes, copias de las teotihuacanas de la pirámide de Quetzalcoatl (figura 15), en tanto que en los extremos de la fachada había dos glifos en relieve, inspirados en la lapidaria mexica. Este edificio fue importante en su momento por las proporciones del espacio interno que tenía.

Es bien conocida la influencia del arte maya sobre el estilo Art Deco, Mariscal no podía sustraerse a ella, máxime que conocía bien la ałquitectura de Yucatán. Cuando en 1930 se encarga de concluir las obras del Palacio de Bellas Artes, lo maya aparece en los cuatro grandes mascarones que rematan los pilares lampadarios; en este caso la ornamentación del Codz Pop de Kabah, Yucatán, sirvió de modelo (figura 16). Los mascarones, diseñados por el propio Mariscal, los ejecutó en metal la casa Edgar Brandt de París. Desde el punto de vista decorativo fueron todo un éxito y una aportación original del Art Deco. Chac era el dios del agua entre los mayas y Tláloc lo fue para los habitantes del altiplano, curiosamente Mariscal dispuso cuatro representa. ciones del Tláloc teotihuacano en las puertas de ingreso a la gran sala de espectáculos.

Aparte de los ejemplos indicados Federico E. Mariscal empleó otros motivos prehispánicos en la ornamentación del Palacio de Bellas Artes; su intervención en el edificio le sirvió para imprimirle un cierto aire nacional, así como también pata manifestar su tendencia hacia el eclec. ticismo, por ello no resulta raro que un año más tarde, en 1935, se mani. festara en la otra cara del nacionalismo arquitectónico: la colonial, al construir el segundo edificio del Ayuntamiento de la ciudad de México.

Con un sentido deliberadamente nacionalista o con un propósito ayuno de toda intención política, algunos arquitectos se han preocupado por encontrar las raíces culturales de este país para recrearlas en las obras que construyen, y mostrar así lo que es propio ante los pode. rosas influencias que llegan del exterior. Tal esfuerzo, en ambos casos, no ha sido fácil ni siempre afortunado, de allí que no todo lo que se ha hecho haya alcanzado notoria importancia. A continuación se ofre. cen otros ejemplos en los que sus autores quisieron imprimir la presen. cia de la herencia prehispánica, según los personales conceptos que sobre la misma tuvieron y las formas en que la manifestaron en las empresas arquitectónicas que acometieron. 
Dentro de la corriente Art Deco quedan situados dos edificios levantados en la década de los años veinte. El primero es el de la Asociación Cristiana Femenina (1923-1933). Aquí mediante relieves integrados al aplanado de los muros, el arquitecto y escultor José Luis Cordero, realizó una estilizada decoración lineal con figuras femeninas, águilas y otros motivos indígenas, productos más de su fantasía que no de la realidad arqueológica; sin embargo, los relieves son una manifestación de originalidad no siempre alcanzada en México con ese estilo. ${ }^{33}$ El otro edificio es el que hacia 1928 construyeron los arquitectos Guillermo Zárraga y Vicente Mendiola Q., para una central de la policía y cuerpo de bomberos, de acuerdo con estos últimos, simbólicamente se dispu. sieron en la esquina dos enormes relieves en chiluca con mascarones de Chalchiutlicue, la diosa del agua (figura 17).

A las tentaciones indigenistas no escaparon los arquitectos del funcionalismo como Juan O'Gorman y Enrique Yáñez; el primero en un proyecto para un edificio de departamentos proponía en la composición ornamental de los cuatro niveles y el remate de la construcción, grandes grecas de inspiración zapoteca. A Yáñez, autor de una significativa obra dentro del funcionalismo, no le han pasado desapercibidos los valores estéticos del arte prehispánico, los ha recreado en su propia residencia (1961), y en colaboración con José Chávez Morado en el Centro Médico Nacional. A otros arquitectos se deben obras fallidas, como el grotesco Monumento a La Raza (1940) debido a Luis Lelo de Larrea, quien lo concibió como una pirámide con grupos escultóricos, todo hechos en cemento armado. En la década de los años cuarenta la cons. trucción de grandes salas para proyecciones cinematográficas alcanzaron gran auge; al arquitecto Francisco Serrano se deben algunas de las más significativas. Lo prehispánico encontró su manifestación en el cine Popotla, de autor anónimo (figuras 19 y 20). Entre otras obras, noto. rias sólo por lo discutible que son en sí, se cía únicamente el Musco del Anahuacalli (1945) de Diego Rivera.

En las ciudades del interior de la República es muy posible que existan edificios en los que la presencia de la ornamentación prehispánica responda a los propósitos nacionalistas de identificación con lo propio, por desgracia este trabajo se ha circunscrito, salvo el caso de Sevilla, al

\footnotetext{
33 Fueron autores del mismo, según, la inscripción alusiva, I S. Gore como arquitecto constructor, José A Cuevas intervino como ingeniero responsable y $\overline{\mathbf{s}}$. Adam como Director Iécnico de la obra. Se localiza en la esquina de la Avenida Morelos y la calle de Humboldt.
} 
estudio de lo construido en la ciudad de México. Como ejemplo de lo que puede haber en otras poblaciones se muestra aquí la "casa azteca" que existió hasta 1982 en Monterrey, Nuevo León (figura 18). En la misma ciudad fronteriza con Estados Unidos de Norteamérica, en el antiguo Palacio Federal, obra de 1930, las alfardas de las escaleras terminan en cabezas de serpientes mexicas.

Alberto T. Arai, un teórico de la arquitectura mexicana contemporánea cuyos escritos están en espera de estudio, mantuvo viva la preocupación de encontrar la conjunción posible de la antigua arquitectura indígena, con los principios constructivos de la actual. Conforme a sus ideas estuvo acertado en las canchas de frontón que construyó en la Ciudad Universitaria (1950). Tanto la forma piramidal adoptada en cada cancha, como su recubrimiento de piedra basáltica, fueron un acier. to y les confieren un sello inconfundible de identificación con las viejas culturas del altiplano. Agréguese a eso la integración perfecta que se logró con el medio del paisaje natural en que se encuentran y se expli. ca así la autonomía que mantienen al lado de los edificios funcionalistas que les son vecinos. Los frontones de Arai se cuentan entre los mejores logros de una expresión nacional.

Producto de una conciencia bien definida respecto a lo que se quiere alcanzar, tal es el origen de la magna obra del Colegio Militar debida al talento e imaginación de los arquitectos Agustín Hernández y Manuel González Rul. De las diversas obras que aquí se han estudiado como manifestaciones del nacionalismo en la arquitectura, ninguna como ésta ha logrado una realización semejante. En el Colegio Militar se ha integrado hábilmente la presencia formal de la herencia prehispánica con las más esmeradas soluciones del urbanismo y la arquitectura contemporánea.

Io primero que sorprende ante la vista del conjunto es la amplitud de sus espacios abiertos y la disposición de los edificios en torno a los mismos; el punto de referencia frente a esta concepción de grandiosidad se encuentra en las plazas ceremoniales de centros como Teotihuacán o Monte-Albán. El amplio Patio de Honor del Colegio Militar tiene su origen en el estudio que sus autores debieron hacer en los xeferidos conjuntos prehispánicos (figura 21). Otro tanto sucede en la composición de la plaza del cuariel para el batallón de servicios e instrucción, su filiación de ciudadela indígena es evidente. Al respecto el arquitecto Hernández declaró que "... el proyecto del Heroico Colegio Militar en su conjunto tiene una reminiscencia en los centros ceremoniales prehispá. 
nicos donde se conjugan los espacios abiertos y los construidos, formando plazas y donde las montañas que lo circundan son un remate de los edificios y forman una muralla natural..." ${ }^{34}$

Tanto Agustín Hernández como Manuel González Rul, son arquitectos que conceden notoria atención a las formas, ambos las saben manejar con sorprendentes resultados visuales por su plasticidad. En el formalismo de las antiguas construcciones indígenas encontraron las raíces de las cuales partir para el diseño de las distintas dependencias que constituyen el Colegio Militar, fue así como recrearon las formas piramidales, los muros en talud, las escalinatas y en algún caso llegaron, incluso, hasta el simbolismo, como sucedió con el gimnasio. ${ }^{35}$ Partir de formas ya establecidas para lograr nuevas expresiones, implica el enfrentarse a riesgos no siempre superables, sin embargo, en la composición arquitectónica de la fachada del Edificio de Gobierno, se alcanzó una originalidad en contadas ocasiones obtenida, al crearse una nueva imagen del dios Tláloc. En realidad la fachada no es otra cosa que un gigantesco mascarón de la deidad del agua en cuya representación se llegó a una abstracción geométrica, acorde por lo demás al arte del siglo xx. Por otra parte el nuevo rostro de Tláloc significa el reconocimiento hacia un pasado que nos pertenece y que continúa vivo cuando se le inter. preta con talento (figura 23).

El nacionalismo y su expresión en la arquitectura mexicana, tal ha sido el tema estudiado en este trabajo, mediante los ejemplos más significativos de una labor realizada en distintas épocas, por diversos arquitectos, en quienes la conciencia de ser poseedores de una herencia existente en los edificios de las antiguas culturas indigenas del pais, les ha llevado a buscar las expresiones formales que consideraban apropiadas a fin de dar razón en sus obras, de la existencia de valores distintivos frente a lo extranjero, en lo cual no está ausente un propósito de afirmación. Como se ha visto, en algunos casos se extremó la nota en un afán ilimitado de hacer patente lo propio; en otros, la mesura y el talen-

34 Véase, Agustín Hernández Navaro, "Heroico Colegio Militar", En Lineas, Axquitectura y Diseño, núm. 2, Universidad Anáhuac, México, mayo de 1979.

35. A una pregunta que le hiciera Louise Noelle al arquitecto Hernández, éste contestó: "respecto al gimnasio efectivamente tiene un aspecto engañoso... Nunca pensé que pareciera un edificio hundido, porque nunca lo situé con el marco del paisaje Siempre lo vi como un remate simbolizando el crótalo de una serpiente..." En una mesa redonda después de efectuar una visita al Colegio Militar, el 18 de mayo de 1977. Para un conocimiento de la labor de este arquitecto se recomienda el libro de Louise Noelle, Agustin Hernández, México, UNAM, 1982. 
to han sido los factores con los cuales se han logrado obras singulares y representativas de los valores culturales de este pueblo. La última obra estudiada, la del Colegio Militar, está lejos de cerrar el ciclo de la arquitectura nacionalista en su expresión indigenista, es tal la fuerza de ese pasado heredado que nada difícil es que vuelva aparecer con otra interpretación, en un futuro imprevisible por lo demás. 